Provided for non-commercial research and education use. Not for reproduction, distribution or commercial use.

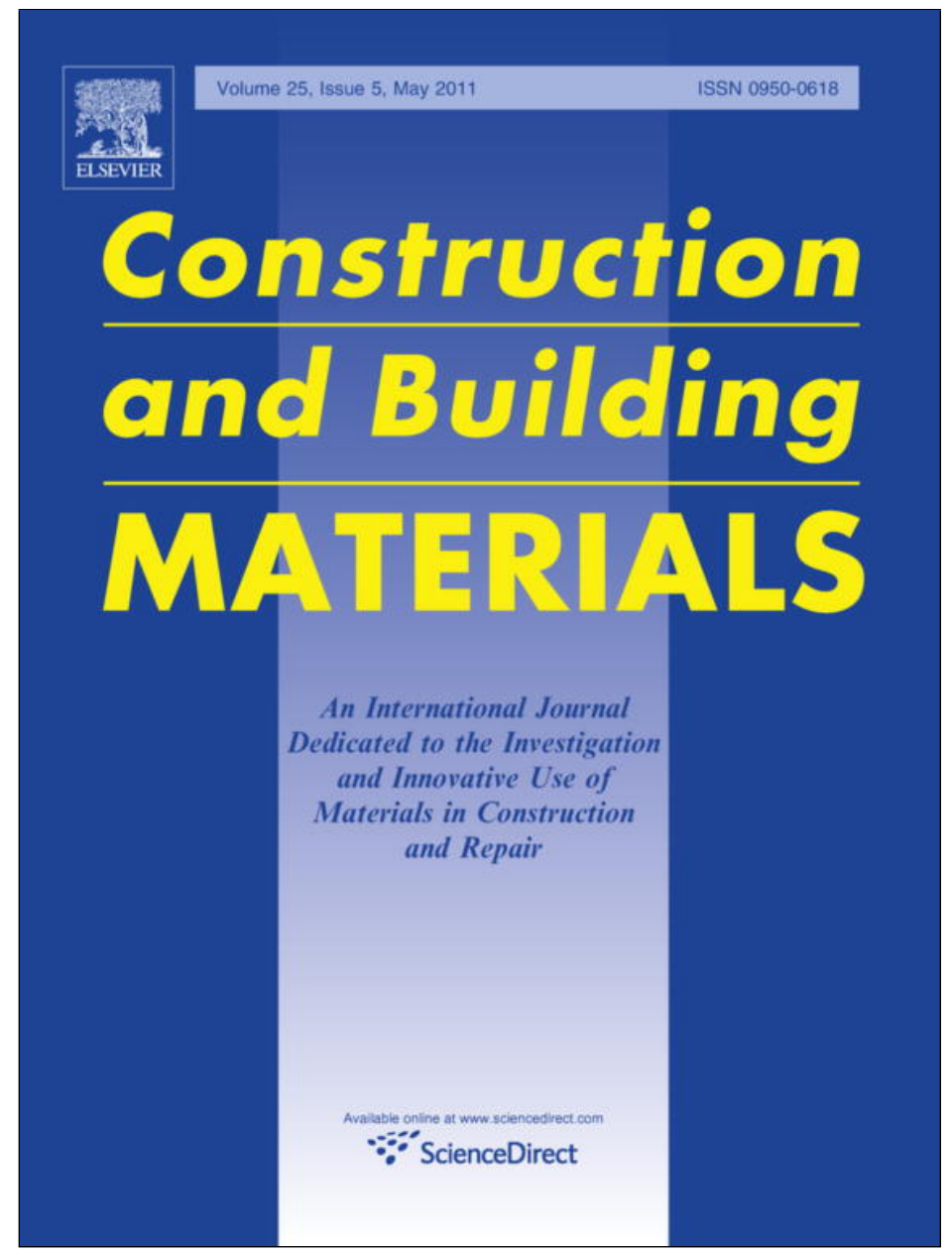

This article appeared in a journal published by Elsevier. The attached copy is furnished to the author for internal non-commercial research and education use, including for instruction at the authors institution and sharing with colleagues.

Other uses, including reproduction and distribution, or selling or licensing copies, or posting to personal, institutional or third party websites are prohibited.

In most cases authors are permitted to post their version of the article (e.g. in Word or Tex form) to their personal website or institutional repository. Authors requiring further information regarding Elsevier's archiving and manuscript policies are encouraged to visit:

http://www.elsevier.com/copyright 


\title{
On the size and shape of initial out-of-plane curvatures in structural glass components
}

\author{
Jan Belis $^{\mathrm{a}, *}$, Danijel Mocibob ${ }^{\mathrm{b}, 1}$, Andreas Luible ${ }^{\mathrm{b}, 2}$, Marc Vandebroek ${ }^{\mathrm{a}}$ \\ ${ }^{a}$ Department of Structural Engineering - LMO, Ghent University, Technologiepark-Zwijnaarde 904, B-9052 Ghent, Belgium \\ ${ }^{\mathrm{b}}$ Steel Structures Laboratory - ICOM, Swiss Federal Institute of Technology - EPFL, GC B3 505, Station 18, CH-1015 Lausanne, Switzerland
}

\section{A R T I C L E I N F O}

\section{Article history:}

Received 29 July 2010

Received in revised form 19 November 2010

Accepted 7 December 2010

Available online 31 December 2010

\section{Keywords:}

Structural glass

Initial geometrical imperfection

Initial curvature

Flatness

Overall bow

Buckling

Flexural buckling

Lateral torsional buckling

Glass beam

Glass column

\begin{abstract}
A B S T R A C T
For many structural glass components, buckling is known to be a major design issue, which is influenced significantly by several parameters. The latter include boundary conditions, slenderness and geometrical imperfections, in particular initial curvatures. However, in spite of their importance for building practice, experimental data for the latter are very poorly documented. Consequently, an extended experimental campaign is presented in which initial curvatures of 312 monolithic and laminated glass beams with a variable length, height, glass thickness, glass type and - wherever applicable - interlayer, have been accurately measured and analysed. Major conclusions have been drawn regarding the shape and the size of initial curvatures.
\end{abstract}

(C) 2010 Elsevier Ltd. All rights reserved.

\section{Introduction}

Over the last two decades, the use of glass as a load-bearing structural material has grown in a relatively spectacular way. Typical examples include glass stairs, roofs, accessible floors, beams, columns, shear walls, etc. [1-3]. Even if official design standards or recommendations for most of those applications are still lacking in most countries, a large number of scientific investigations has been carried out in this field, providing useful information for glass designing professionals. Amongst the research focusing on the load-bearing capacity of simple glass components (i.e. without connection devices, etc.), two major research areas could be detected.

A first group of researchers focuses on strength-related issues, such as brittleness, fracture mechanics and probabilistic reliability of glass. In particular the tensile strength of glass is of interest for structural applications, as it is well-known to be significantly lower

\footnotetext{
* Corresponding author. Tel.: +32 9264 5478; fax: +32 92645838.

E-mail address: jan.belis@UGent.be (J. Belis).

1 Present address: RI ISA, Permasteelisa Group, Delta 5, 51000 Riejeka, Croatia.

2 Present address: Lucerne University of Applied Sciences and Arts, Technikumstrasse 21, 6048 Horw, Switzerland.
}

than the compressive strength. Apart from the many contributions in specialised material science literature, several authors investigated these subjects from a structural engineering point of view [4-9].

In addition, a second group of researchers concentrated on stability problems, such as flexural buckling, torsional buckling, lateral torsional buckling, plate buckling and shear buckling [10-18]. Those stability issues are of particular interest when glass elements, which are usually very slender, are subjected to axial compressive loads, as in such cases the (elastic) buckling load will often be more critical than the glass breakage load.

For designing purposes, most parameters influencing the buckling resistance of monolithic or laminated glass are relatively easily accessible (e.g. the glass geometry, which is a given; the interlayer properties, which are available from the manufacturer or in literature; or loading and mounting eccentricities, which follow from tolerances and from the design concept itself). However, information on initial shape imperfections, which according to several authors often play a rather important role regarding the stability of structural glass members [10-12,18], is scarce and scattered. The typical influence of initial curvature on the elastic buckling resistance of a bar in compression is illustrated in Fig. 1.

Consequently, the main objectives of this contribution are the following: 


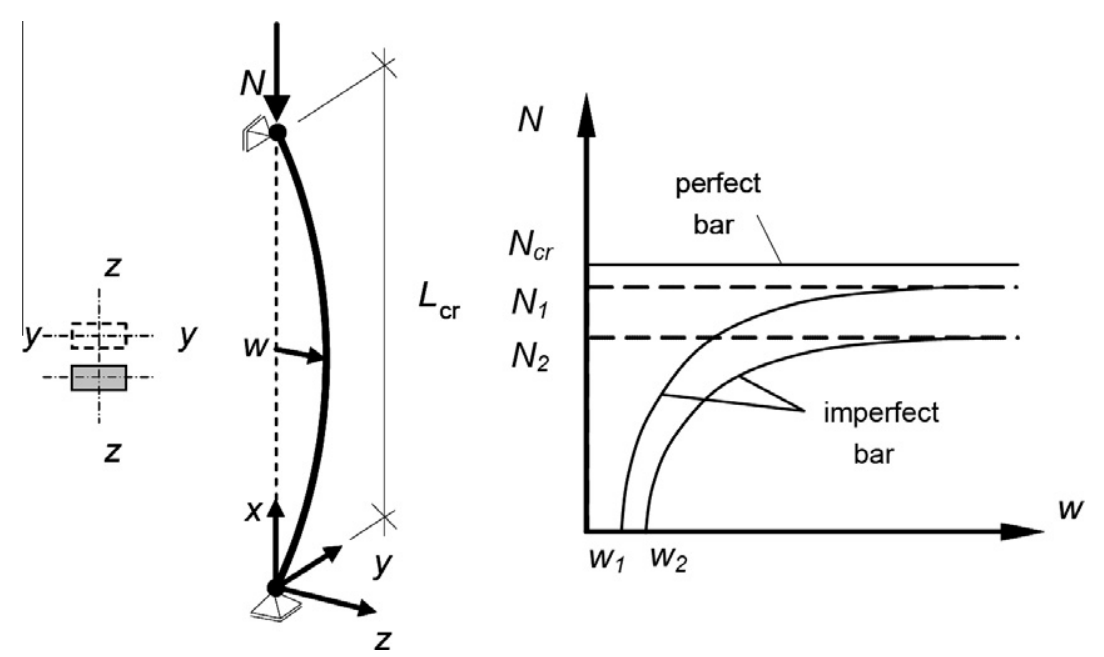

Fig. 1. Typical influence of initial curvature $w$ on the elastic buckling resistance $N$ of a bar in compression.

Table 1

Overview of specimens tested at UGent. All specimens had polished edges. Glass types A, HS and T represent annealed, heat-strengthened and tempered glass respectively.

\begin{tabular}{|c|c|c|c|c|c|c|c|c|}
\hline Lamination & Glass type & $\begin{array}{l}\text { Interlayer } \\
\text { material }\end{array}$ & $\begin{array}{l}\text { Length } \\
L(\mathrm{~mm})\end{array}$ & $\begin{array}{l}\text { Width } \\
W(\mathrm{~mm})\end{array}$ & $\begin{array}{l}\text { Length/Width } \\
L / W(-)\end{array}$ & $\begin{array}{l}\text { Glass thickness } \\
t(\mathrm{~mm})\end{array}$ & $\begin{array}{l}\text { Number of } \\
\text { specimens }\end{array}$ & $\begin{array}{l}\text { Manu } \\
\text { facturer }\end{array}$ \\
\hline \multirow[t]{25}{*}{ Laminated } & A & PVB & 3000 & 120 & 25 & $2 \times 6$ & 4 & A \\
\hline & & PVB & 3000 & 120 & 25 & $2 \times 8$ & 4 & A \\
\hline & & PVB & 3000 & 150 & 20 & $2 \times 6$ & 4 & A \\
\hline & & PVB & 3000 & 150 & 20 & $2 \times 8$ & 4 & A \\
\hline & & PVB & 3000 & 300 & 10 & $2 \times 10$ & 5 & B \\
\hline & & SG & 3000 & 120 & 25 & $2 \times 6$ & 4 & C \\
\hline & & SG & 3000 & 120 & 25 & $2 \times 8$ & 4 & C \\
\hline & & SG & 3000 & 150 & 20 & $2 \times 6$ & 4 & C \\
\hline & & SG & 3000 & 150 & 20 & $2 \times 8$ & 4 & C \\
\hline & & SG & 3000 & 200 & 15 & $2 \times 6$ & 4 & C \\
\hline & & SG & 3000 & 200 & 15 & $2 \times 8$ & 4 & C \\
\hline & & SG & 3000 & 300 & 10 & $2 \times 8$ & 4 & C \\
\hline & HS & PVB & 3000 & 300 & 10 & $2 \times 10$ & 5 & B \\
\hline & & SG & 3000 & 120 & 25 & $2 \times 8$ & 4 & C \\
\hline & & SG & 3000 & 150 & 20 & $2 \times 6$ & 4 & C \\
\hline & & SG & 3000 & 150 & 20 & $2 \times 8$ & 4 & $\mathrm{C}$ \\
\hline & $\mathrm{T}$ & PVB & 3000 & 200 & 15 & $2 \times 6$ & 8 & A \\
\hline & & PVB & 3000 & 300 & 10 & $2 \times 10$ & 5 & B \\
\hline & & SG & 3000 & 150 & 20 & $2 \times 8$ & 4 & C \\
\hline & & SG & 3000 & 200 & 15 & $2 \times 6$ & 4 & A \\
\hline & & SG & 3000 & 200 & 15 & $2 \times 8$ & 4 & A \\
\hline & & SG & 3000 & 200 & 15 & $2 \times 8$ & 4 & C \\
\hline & & SG & 3000 & 300 & 10 & $2 \times 6$ & 4 & A \\
\hline & & SG & 3000 & 300 & 10 & $2 \times 6$ & 4 & C \\
\hline & & SG & 3000 & 300 & 10 & $2 \times 8$ & 4 & A \\
\hline
\end{tabular}

(1) To present an extended experimental campaign and to discuss its results in order to determine the shape and the characteristic value of the maximum amplitude of initial geometrical imperfections (i.e. global bow) of various beam-like glass panes.

(2) To detect trends in imperfection shapes and sizes with respect to other parameters, such as glass thickness, geometric aspect ratio, glass type, lamination and interlayer material.

\section{Test specimens}

An extended experimental campaign has been executed to measure the initial curvature of a variety of glass beams, which have been subjected to buckling tests afterwards. However, the latter are beyond the scope of this contribution: the interested reader will find more details in literature [11,12]. The current focus is on the initial curvature measurement campaign, which was divided in two parts and executed at two different research labs. The first part of the experiments was organised at the Laboratory for Research on Structural Models (LMO) at Ghent University (UGent), Belgium, whereas the second part was organised at the Steel Structures Laboratory (ICOM) of the Swiss Federal Institute of Technology (EPFL), Switzerland. In total, 312 specimens with a different glass type, geometry, manufacturer and - wherever applicable: interlayer - have been tested. An overview of all test specimens is presented in Tables 1 and 2.

\section{Methods}

3.1. Measurement according to EN 1863-1 and EN 12150

In EN 1863-1 and EN 12150 a standard method is given to determine the overall and local bow of respectively heat-strengthened soda lime silicate glass [19] and thermally toughened soda lime silicate safety glass [20]. According to these standards, the glass pane should be placed in a vertical position and supported on its longer edge by two load-bearing blocks in the quarter points. Subsequently, the deformation in terms of global bow must be measured along the edges and 
Table 2

Overview of specimens tested at EPFL. All specimens had polished edges. Glass types A, HS and T represent annealed, heat-strengthened and tempered glass respectively.

\begin{tabular}{|c|c|c|c|c|c|c|c|c|}
\hline Lamination & Glass type & $\begin{array}{l}\text { Interlayer } \\
\text { material }\end{array}$ & $\begin{array}{l}\text { Length } \\
L(\mathrm{~mm})\end{array}$ & $\begin{array}{l}\text { Width } \\
W(\mathrm{~mm})\end{array}$ & $\begin{array}{l}\text { Length/Width } \\
L / W(-)\end{array}$ & Glass thickness $t(\mathrm{~mm})$ & $\begin{array}{l}\text { Number of } \\
\text { specimens }\end{array}$ & $\begin{array}{l}\text { Manu- } \\
\text { facturer }\end{array}$ \\
\hline \multirow[t]{14}{*}{ Laminated } & \multirow[t]{10}{*}{ HS } & PVB & 600 & 200 & 3 & $2 \times 8$ & 3 & $\mathrm{D}$ \\
\hline & & PVB & 600 & 200 & 3 & $2 \times 10$ & 3 & $\mathrm{D}$ \\
\hline & & PVB & 800 & 200 & 4 & $2 \times 8$ & 5 & $\mathrm{D}$ \\
\hline & & PVB & 800 & 200 & 4 & $2 \times 10$ & 5 & $\mathrm{D}$ \\
\hline & & PVB & 1200 & 200 & 6 & $2 \times 8$ & 5 & $\mathrm{D}$ \\
\hline & & PVB & 1200 & 200 & 6 & $2 \times 10$ & 5 & $\mathrm{D}$ \\
\hline & & PVB & 1600 & 200 & 8 & $2 \times 8$ & 3 & $\mathrm{D}$ \\
\hline & & PVB & 1600 & 200 & 8 & $2 \times 10$ & 3 & $\mathrm{D}$ \\
\hline & & PVB & 2000 & 200 & 10 & $2 \times 10$ & 3 & $\mathrm{D}$ \\
\hline & & PVB & 3000 & 300 & 15 & $2 \times 10$ & 3 & $\mathrm{E}$ \\
\hline & \multirow[t]{4}{*}{$\mathrm{T}$} & PVB & 900 & 200 & 4.5 & $2 \times 10$ & 5 & $\mathrm{E}$ \\
\hline & & PVB & 1140 & 200 & 5.7 & $2 \times 10$ & 5 & $\mathrm{E}$ \\
\hline & & PVB & 1380 & 200 & 6.9 & $2 \times 10$ & 5 & E \\
\hline & & PVB & 2000 & 200 & 10 & $2 \times 10$ & 5 & $\mathrm{E}$ \\
\hline \multirow[t]{28}{*}{ Monolithic } & A & - & 350 & 200 & 1.75 & 10 & 9 & $\mathrm{D}$ \\
\hline & \multirow[t]{15}{*}{ HS } & - & 350 & 200 & 1.75 & 8 & 12 & $\mathrm{D}$ \\
\hline & & - & 350 & 200 & 1.75 & 10 & 12 & $\mathrm{D}$ \\
\hline & & - & 600 & 200 & 3 & 8 & 3 & $\mathrm{D}$ \\
\hline & & - & 600 & 200 & 3 & 10 & 3 & $\mathrm{E}$ \\
\hline & & - & 600 & 200 & 3 & 10 & 3 & $\mathrm{D}$ \\
\hline & & - & 800 & 200 & 4 & 8 & 5 & $\mathrm{D}$ \\
\hline & & - & 800 & 200 & 4 & 10 & 5 & $\mathrm{D}$ \\
\hline & & - & 800 & 200 & 4 & 10 & 6 & $\mathrm{E}$ \\
\hline & & - & 900 & 200 & 4.5 & 10 & 2 & $\mathrm{E}$ \\
\hline & & - & 1140 & 200 & 5.7 & 10 & 2 & $\mathrm{E}$ \\
\hline & & - & 1200 & 200 & 6 & 8 & 5 & $\mathrm{D}$ \\
\hline & & - & 1200 & 200 & 6 & 10 & 5 & $\mathrm{D}$ \\
\hline & & - & 1600 & 200 & 8 & 8 & 3 & $\mathrm{D}$ \\
\hline & & - & 1600 & 200 & 8 & 10 & 3 & $\mathrm{D}$ \\
\hline & & - & 3000 & 200 & 15 & 10 & 4 & E \\
\hline & \multirow[t]{12}{*}{$\mathrm{T}$} & - & 350 & 200 & 1.75 & 8 & 9 & $\mathrm{D}$ \\
\hline & & - & 350 & 200 & 1.75 & 10 & 9 & $\mathrm{D}$ \\
\hline & & - & 660 & 200 & & 10 & 3 & $\mathrm{E}$ \\
\hline & & - & 900 & 200 & 4.5 & 10 & 3 & $\mathrm{E}$ \\
\hline & & - & 1140 & 200 & 5.7 & 10 & 5 & E \\
\hline & & - & 1200 & 200 & 6 & 10 & 5 & $\mathrm{D}$ \\
\hline & & - & 1200 & 200 & 6 & 15 & 6 & $\mathrm{D}$ \\
\hline & & - & 1380 & 200 & 6.9 & 10 & 9 & $\mathrm{E}$ \\
\hline & & - & 1600 & 200 & 8 & 15 & 5 & $\mathrm{D}$ \\
\hline & & - & 1700 & 200 & 8.5 & 10 & 5 & E \\
\hline & & - & 2100 & 200 & 10.5 & 10 & 3 & E \\
\hline & & - & 3000 & 200 & 15 & 10 & 3 & E \\
\hline
\end{tabular}

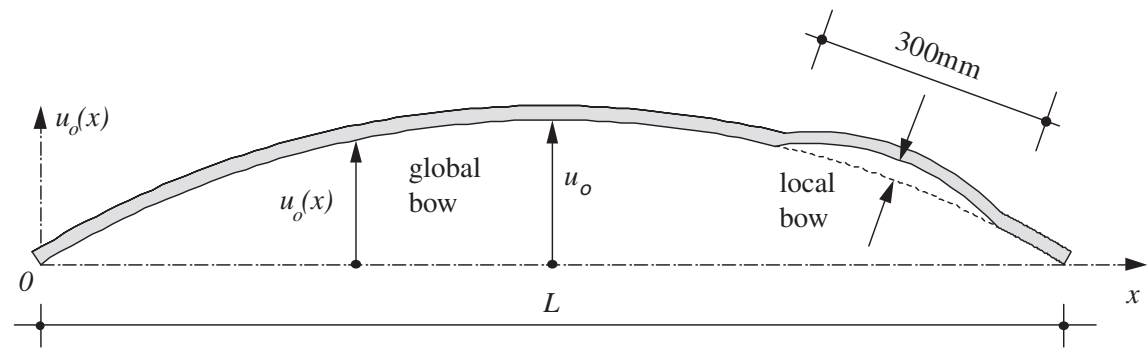

Fig. 2. Measurement of shape imperfections of thermally treated glass according to EN 1863-1 and EN 12150.

diagonals of the glass, as the maximum distance between a straight metal ruler or a stretched wire, and the concave surface of the glass, as depicted in Fig. 2. The value for the global bow is then expressed as the maximum deformation $u_{0}$, in millimetres, divided by the measured length $L$ of the edge or diagonal of the glass, also in millimetres. It should be noted that no standardised method is available to determine general bow of annealed glass, most presumably because it is considered to be perfectly flat.

\subsection{UGent measurement method}

A major objective of the experiments performed at UGent was to obtain more detailed information on the actual shape of the test specimens. As the standard measurement method is providing only information on the (maximum) amplitude of the imperfection, an alternative method is proposed in $\$ 3.2 .1$.

\subsubsection{General overview of test setup}

The main objective was to measure the imperfection amplitude in an automated way at a multitude of positions, equally distributed along the length of the glass specimen, so that a relatively precise approximation of the actual shape could be obtained experimentally.

To do so, the specimens were first placed in vertical position on plywood setting blocks at the quarter points to avoid influence of gravity forces on the natural shape of the glass, in analogy with the standards mentioned in \$3.1. Subsequently, a calibrated linear variable differential transformer (LVDT) was mounted at half height 
of the specimen on a motorised wagon, which could slide on an aluminium guiding rail parallel to the glass specimen. The setup is illustrated in Figs. 3 and 4.

\subsubsection{Compensation of test setup imperfections}

Obviously, the test setup itself was subjected to implicit measurement errors. Different origins of errors existed, such as the precision of the electronic equipment (including LVDT and data acquisition), deviations of the theoretical parallel placement of at the one hand the chord connecting both ends of the specimen and at the other the guiding rail, and geometrical imperfections of the guiding rail. As the first two errors turned out to be not significant, they were not taken into account in the analysis. However, errors due to shape imperfections of the guiding rail were definitely significant, as will be demonstrated in $\S 4.1$ and $\S 5.1$. Consequently, a compensating method was used to eliminate those errors from the analysis.

Firstly, the geometrical imperfection of the guiding rail was deducted from measuring the initial shape imperfections of the same glass specimen twice: once in the conventional position $\left(u_{0, \text { uncorr }, 1}\right)$, and once in mirrored position with respect to the reference rail $\left(u_{0, \text { uncorr, } 2}\right)$. The principle is clarified in Fig. 5 .

Using this principle, the shape imperfections of the guiding rail $u_{0, \text { rail }}$ could be determined analytically with Eq. (1). Repeating this process several times, the imperfections of the guiding rail could be reproduced with high accuracy, so the obtained shape of the guiding rail was adopted to correct any later uncorrected measurements $u_{0, \text { uncorr }}$ on glass specimens. The resulting corrected geometrical imperfection $u_{0}(x)$ at position $x$ was then found by adding (or subtracting, as appropriate) a measurement on a specimen to (or from) the corresponding imperfection of the guiding rail $u_{0, \text { rail }}(x)$, as expressed in Eq. (2).

$u_{0, \text { rail }}(x)=\frac{u_{0, \text { uncorr }, 1}(x)-u_{0, \text { uncorr }, 2}(x)}{2}$

$u_{0}(x)=u_{0, \text { uncorr }}(x) \pm u_{0, \text { rail }}(x)$

\subsection{EPFL measurement method}

The objective of the experiments performed at EPFL was to investigate the amplitude of the initial shape imperfections. Being complementary to the quasicontinuous measurements performed at UGent, only a limited number of welldefined discrete measurements were performed along the glass specimens at EPFL. More specifically, for 123 specimens the amplitude of the initial global bow was manually measured at $25 \%, 50 \%$ and $75 \%$ of the specimen length as the distance

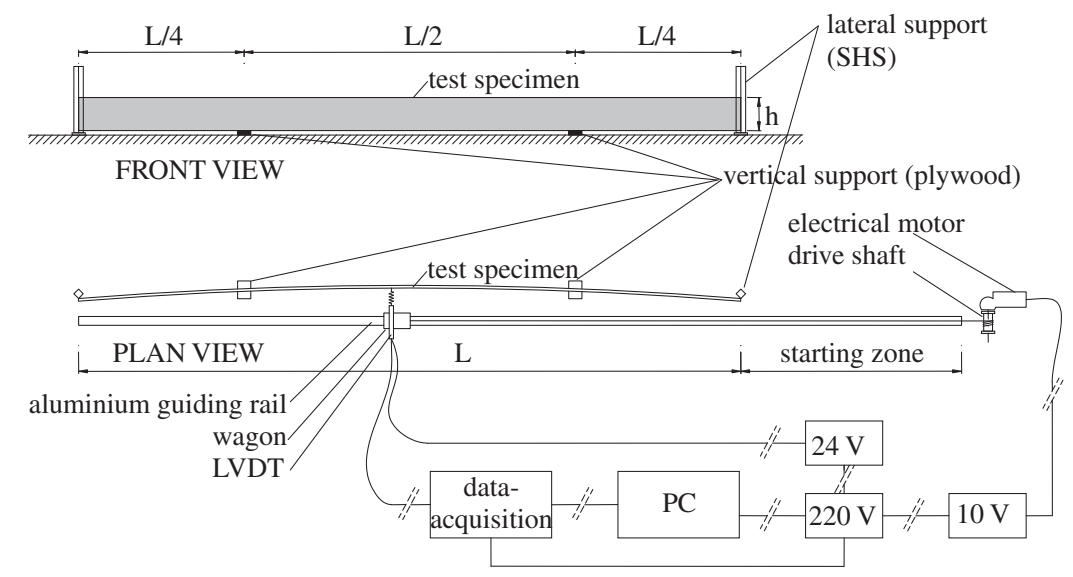

Fig. 3. Schematic overview of UGent imperfection measurement test setup and data acquisition.

(a)

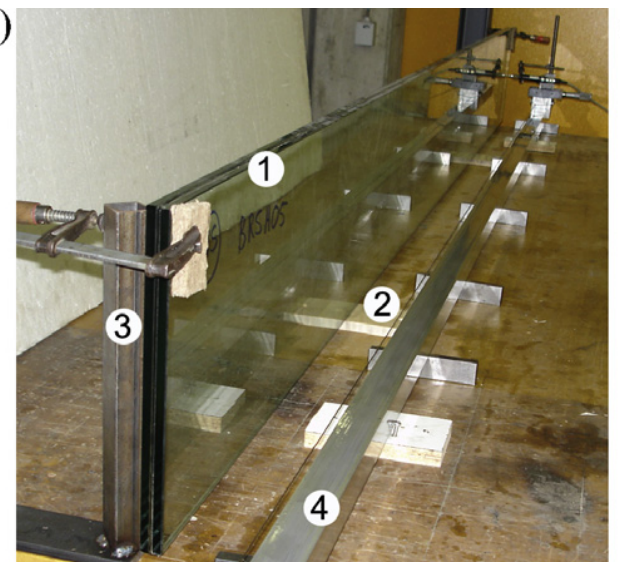

(b)

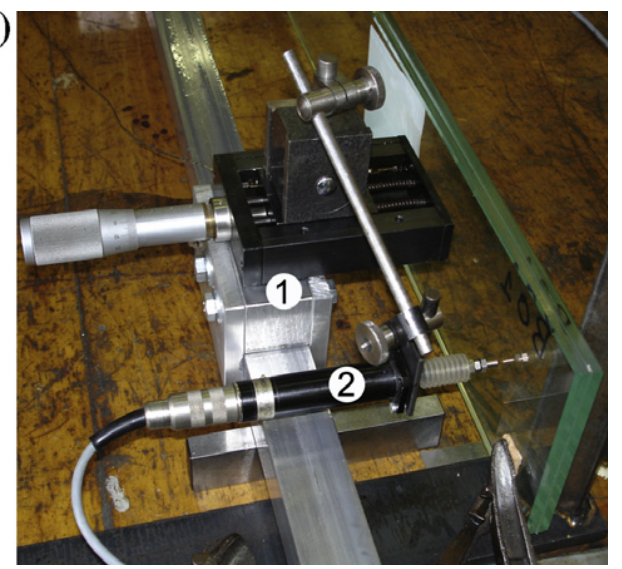

Fig. 4. Initial curvature measurement setup at Ghent University: (a) overview with (1) glass specimen, (2) plywood setting blocks at quarter points, (3) SHS vertical lateral supports at glass ends, and (4) aluminium guiding rail; (b) aluminium guiding rail with (1) sliding wagon and (2) mounted LVDT.

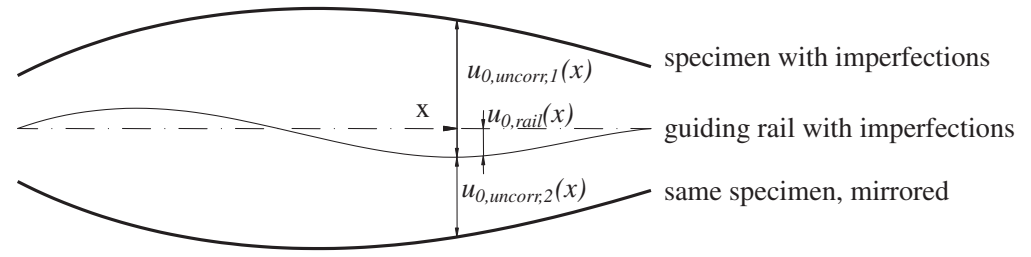

Fig. 5. Elimination of initial shape imperfections of the guiding rail by mirrored measurement of the same test specimen. 
$u_{o}(x)[\mathrm{mm}]$

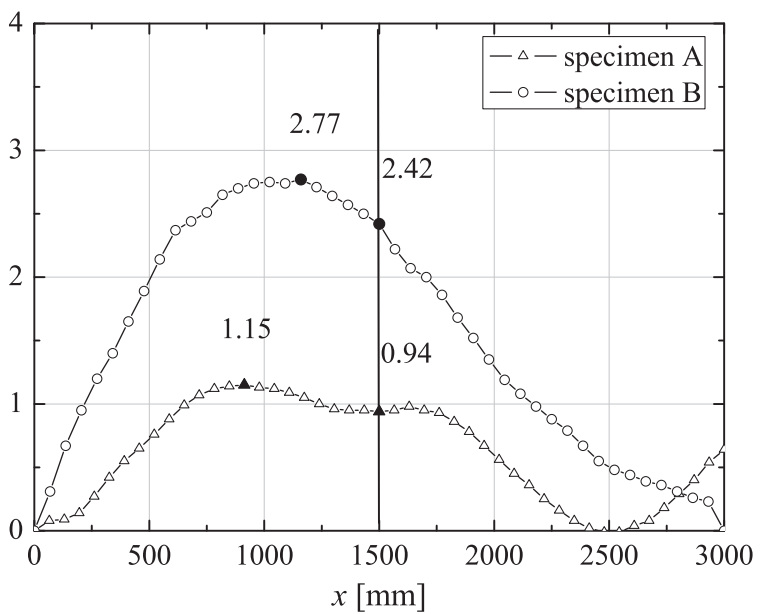

Fig. 6. Examples of atypical specimens with a deviant imperfection shape, illustrating possible errors made when the amplitude would have been measured only at mid span of the specimen instead of at its maximal value.

(a) $u_{o}(x)[\mathrm{mm}]$

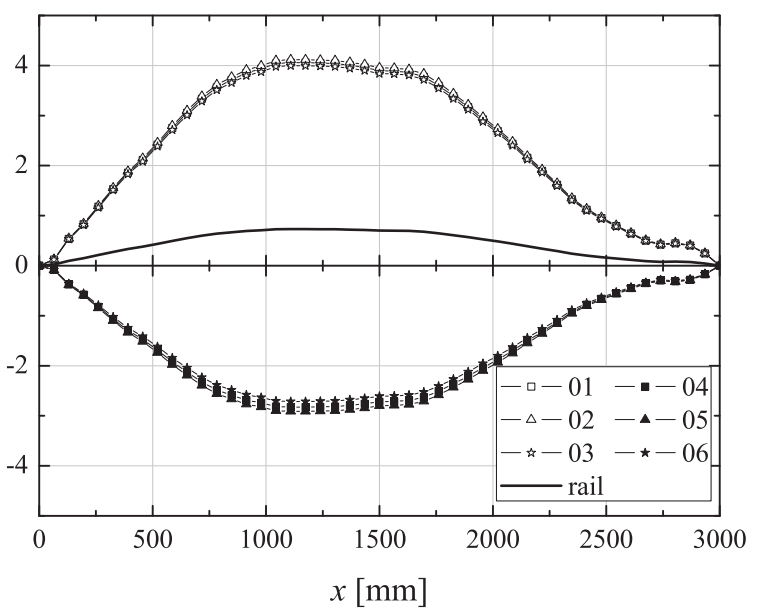

(c) $u_{o}(x)[\mathrm{mm}]$

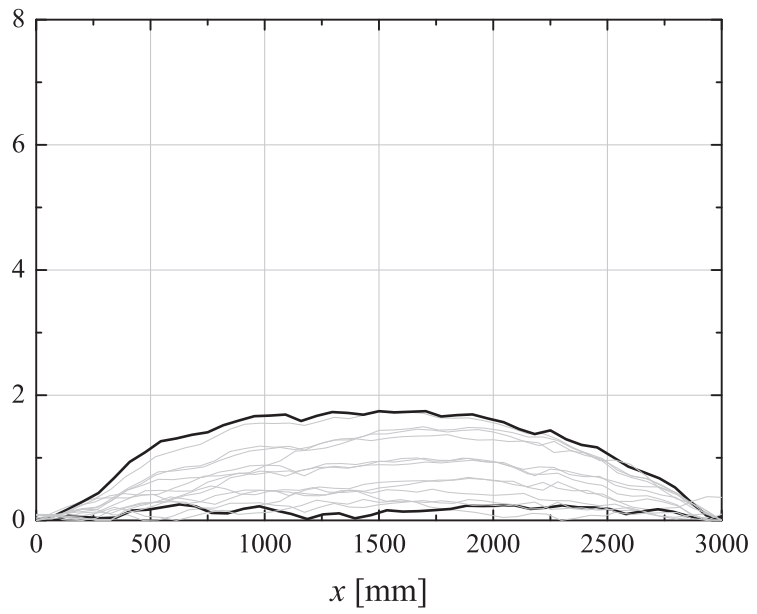

between a tensioned steel reference wire and the glass, more or less following the method of EN 1863-1 and EN 12150 as explained in \$3.1. For 82 other specimens, only a single measurement was done, more specifically at half the specimen length. As will be demonstrated in Section 5.2.2, the initial curvature of the 9 monolithic annealed glass specimens was too small to be measured accurately by the wire method. Consequently, a calliper has been used for these samples.

For a vast majority of samples, this simplified method yielded relatively accurate results, as can also be deducted from the discussion in $\$ 5.1$. However, a limited number of specimens had a rather deviant initial geometrical imperfection shape. Consequently, for such atypical specimens the global bow amplitude measured at half the length deviated rather significantly from the maximum amplitude, which resulted in errors. For an exceptional case, depicted in Fig. 6, this error amounted to about $18 \%$. However, these errors are further ignored in the analyses because the number of specimens with a significantly deviating shape was very limited, as will be demonstrated in $§ 5.1$.

\section{Results}

\subsection{Imperfection shape}

Fig. 7a depicts the initial geometrical imperfections of the aluminium guiding rail, together with the results of three subsequent mirrored measurements on the same specimen, used to determine the imperfections of the guiding rail as explained in \$3.2.2. Furthermore, Fig. $7 \mathrm{~b}-\mathrm{d}$ represent a general overview of the shape

(b) $u_{o}(x)[\mathrm{mm}]$

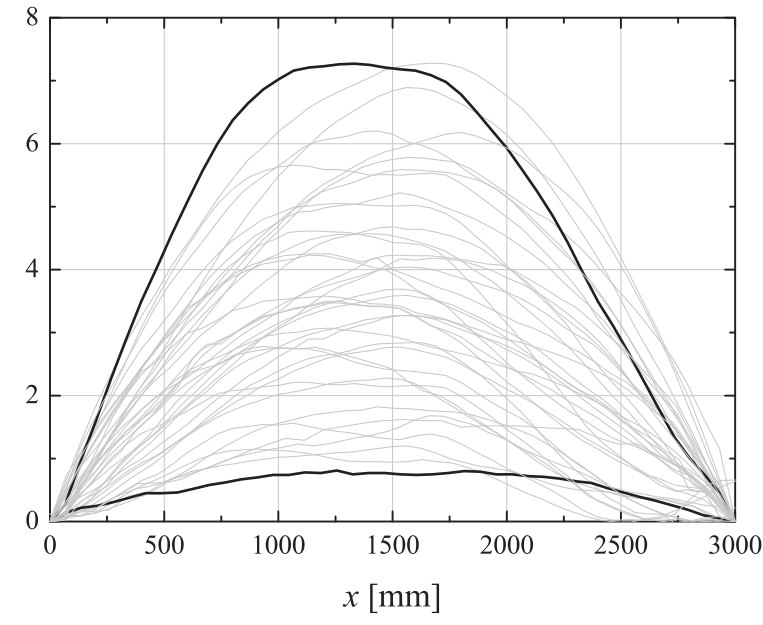

(d) $u_{o}(x)[\mathrm{mm}]$

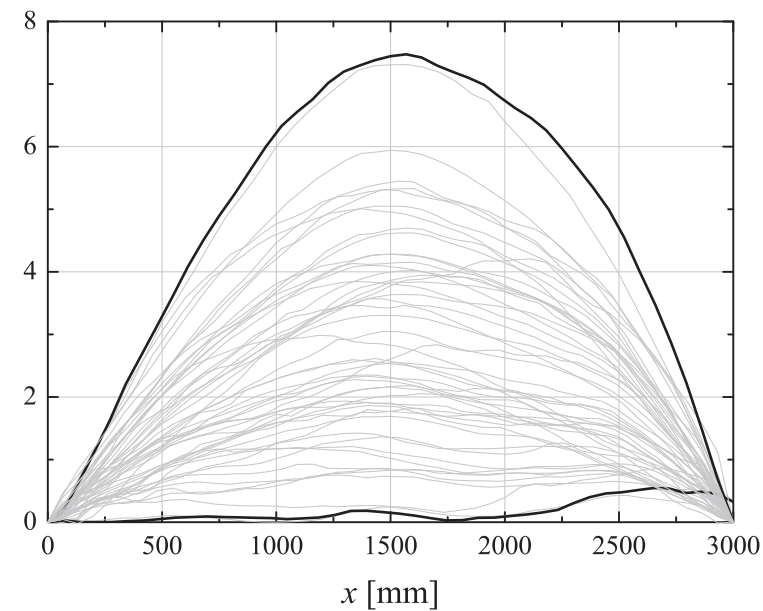

Fig. 7. Initial shape imperfections (curvature): (a) of the aluminium guiding rail, determined on the basis of three mirrored measurements of the same specimen; (b) of specimens provided by manufacturer A; (c) of specimens provided by manufacturer B; (d) of specimens provided by manufacturer $\mathrm{C}$. 
imperfections of all specimens obtained from manufacturer A, B, and $C$, respectively. To avoid the graphs to be too crowded, only the minimum and maximum are shown in black; the other are in grey. It should be noted that with the exception of the measurements done to define the imperfections of the guiding rail, all measurements yield a positive value, meaning that they have been positioned in the test setup in such a way that the concave side of the bow was always directed towards the guiding rail.

\subsection{Curvature size}

In the following, the size of the imperfection $u_{0}$ represents the maximum amplitude (for UGent measurements) or the amplitude at mid span (for EPFL measurements). An overview of all experimentally determined imperfection sizes is depicted in Fig. 8 in function of the length $L$ to width $W$ ratio $L / W$, which will be further referred to as the aspect ratio.

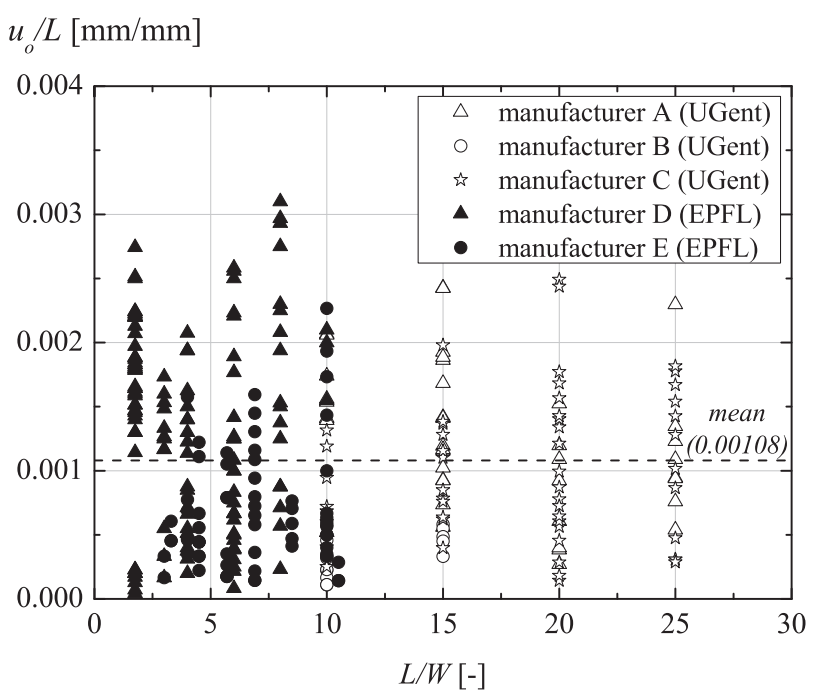

Fig. 8. Overview of amplitude of all imperfection measurements in function of the aspect ratio $L / W$.

(a) $u_{o}(x)[\mathrm{mm}]$

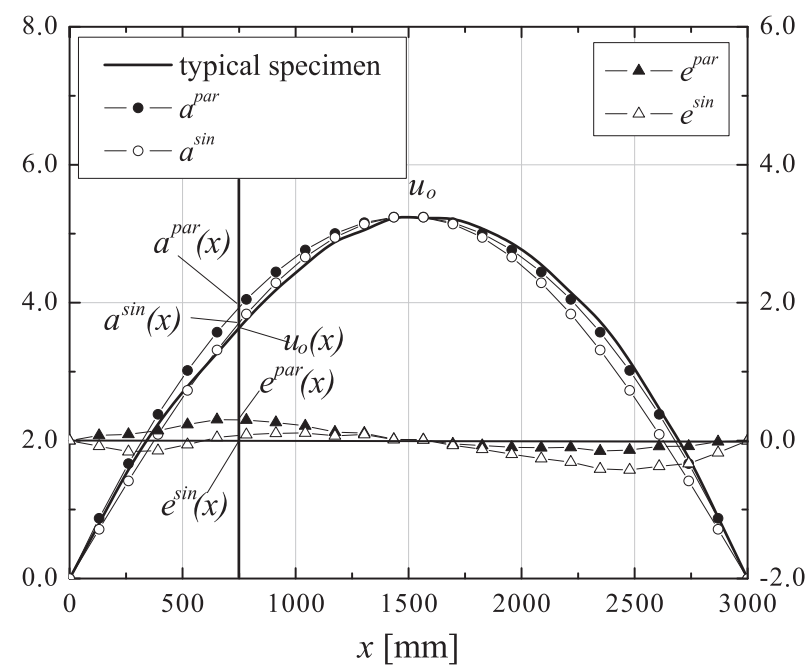

\section{Discussion}

Several parameters are analysed below to determine their influence on the shape and magnitude of the initial imperfections of all glass specimens presented in $\S 2$.

\subsection{Overall bow shape}

As indicated by Fig. 7a, out-of-planeness imperfections of the guiding rail are amounting to a maximum value of almost $1 \mathrm{~mm}$. Consequently, they are considered to be significant and for the further analysis of glass measurements they are included in the analysis according to the methods explained in §3.2.2.

Regarding the shape of initial curvature, no reference nor requirement is available in glass product standards. However, from the experimental results depicted in Fig. $7 \mathrm{~b}-\mathrm{d}$, it is clear that initial curvatures in general could be approximated relatively well by either a second order parabola or a half sinusoidal wave, expressed by Eqs. (3) and (4), respectively.

Second order parabola:

$u_{o}(x)=-\frac{u_{o}}{(0.5 L)^{2}} \cdot x^{2}+\frac{2 \cdot u_{o}}{(0.5 L)} \cdot x$

Sinusoidal wave:

$u_{o}(x)=u_{0} \cdot \sin \left(\frac{x \cdot \pi}{L}\right)$

Fig. 9 depicts the shape approximation of the initial curvature of two randomly chosen specimens. More specifically, the first one had an initial curvature shape which fits the approximated functions very well (as was the case with the majority of the specimens), as can be observed in Fig. 9a. On the other hand, the second one had an initial curvature shape which deviates significantly from the approximate functions displayed in Fig. 9b (as was the case with only a few specimens). The measured initial curvature shape is represented by a bold line, while the parabolic $\left(a^{\text {par }}\right)$ and sinusoidal approximate functions $\left(a^{\text {sin }}\right)$ are represented by filled dots and empty dots respectively. The corresponding amplitude of the imperfection is displayed on the ordinate axis situated on the left hand side of the graphs, whereas the ordinate axis at the right hand side corresponds to the errors, plotted on the

(b) $u_{o}(x)[\mathrm{mm}]$

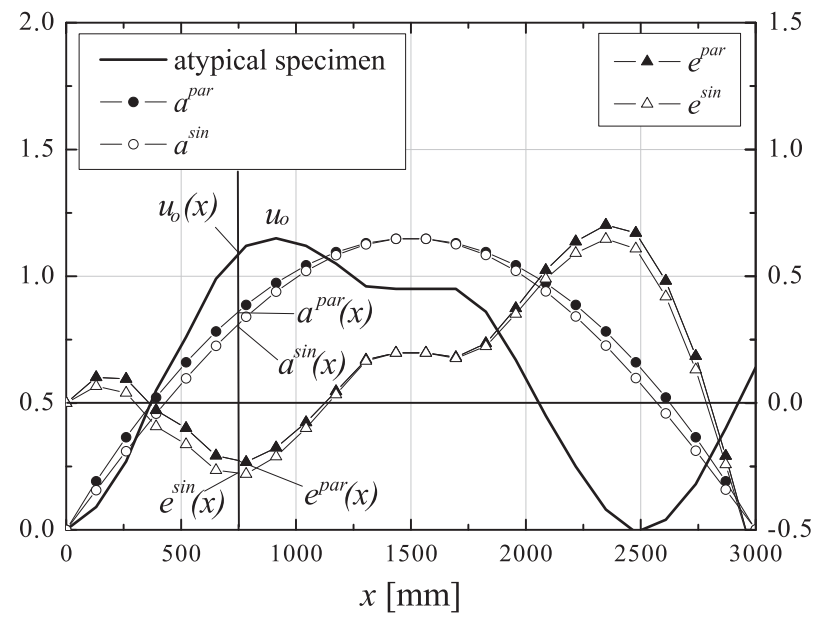

Fig. 9. Measured initial imperfection $u_{0}(x)$, approximation by parabola $\left(a^{\text {par }}\right)$, approximation by sinusoid $\left(a^{\text {sin }}\right)$, error by parabola $\left(e^{\text {par }}\right)$ and error by sinusoid $\left(e^{\text {sin }}\right)$ : (a) for a random typical specimen; (b) for a random atypical specimen. 
(a) $f e^{p a r}[\%]$

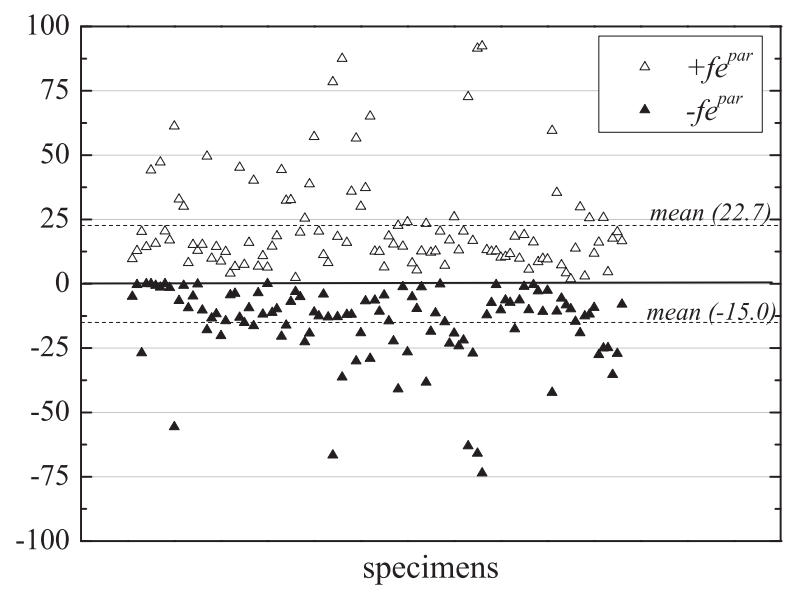

(b) $f e^{\sin }[\%]$

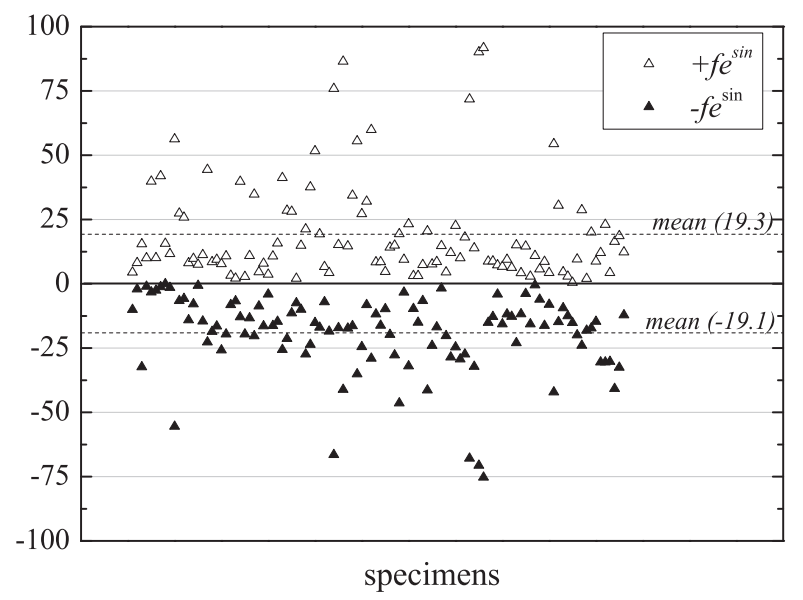

Fig. 10. Fitting errors $(f e)$ and mean values for the entire set of specimens: (a) for a parabolic shape; (b) for a sinusoidal shape.

same graph as the differences between the measured initial curvature and the approximated functions. The errors with respect to the parabolic $\left(e^{p a r}\right)$ and sinusoidal functions $\left(e^{s i n}\right)$ are presented by filled and empty triangles respectively.

To quantitatively describe the approximation quality of the initial imperfection shape, a fitting error $\left(f e^{p a r}\right.$ for the parabola and $f e^{s i n}$ for the sinusoid) is defined here as the ratio of the maximal error ( $e^{\text {par }}$ for the parabola and $e^{\sin }$ for the sinusoid) and the maximal initial imperfection $u_{0}$.

$f e^{p a r}=\frac{e^{p a r}}{u_{0}} \cdot 100[\%]$

$f e^{\sin }=\frac{e^{\sin }}{u_{0}} \cdot 100[\%]$

To make a more elaborated analysis of the fitting error, the shape of the initial geometrical imperfection is further investigated in Fig. 9 and $\mathrm{b}$ at position $x=750 \mathrm{~mm}$, using the following symbols:

$a^{p a r}(x)$ the approximated value of the initial imperfection at position $x$ using a parabolic function.

$a^{\sin }(x)$ the approximated value of the initial imperfection at position $x$ using a sinusoidal function.

$e^{p a r}(x)$ the error at position $x$, expressed as the difference between the measured initial imperfection and the approximated initial imperfection using a parabolic function at position $x$.

$e^{\text {par }}(x)=u_{o}(x)-a^{\text {par }}[\mathrm{mm}]$

$e^{\sin }(x)$ the error at position $x$, expressed as the difference between the measured initial imperfection and the approximated initial imperfection using a sinusoidal function at position $x$

$e^{\mathrm{sin}}=u_{0}(x)-a^{\text {sin }}[\mathrm{mm}]$

From here the fitting error for parabolic approximation $f e^{p a r}$ and for sinusoidal approximation $f e^{\sin }$ are derived using Eqs. (5) and (6), respectively.

When the approximated value has a higher or lower value than the measured initial imperfection, the corresponding fitting error is positive $(+f e)$ or negative $(-f e)$.

From the measured initial imperfection of each specimen the maximal initial imperfection $u_{0}$ is derived. Subsequently, using Eq. (3) and (4), each specimen is approximated with parabolic and sinusoidal functions. The maximal errors are determined using
Eq. (7) and (8). Subsequently, introducing them in Eqs. (5) and (6), respectively, the fitting errors for both parabolic and sinusoidal approximation are defined. Finally, Fig. 10a and b represent all positive and negative fitting errors, for the entire set of UGent specimens using respectively a parabolic $\left(f e^{p a r}\right)$ or a sinusoidal approximation $\left(f e^{s i n}\right)$.

From Fig. 10 it can be noticed that the mean value of the positive fitting error is higher for a parabolic approximation (22.7\%) than for a sinusoidal approximation (19.3\%). Oppositely, in the case of a negative fitting error, the parabolic approximation leads to a smaller value $(-15.0 \%)$ than the sinusoidal approximation $(-19.1 \%)$. Adding in absolute value the means of the positive and negative fitting errors for a parabolic shape $(22.7+15.0=37.7 \%)$ and a sinusoidal shape $(19.3+19.1=38.4 \%)$ leads to the conclusion that both approximations have practically the same amplitude of absolute fitting error. On the other hand, subtracting in absolute value the positive and negative fitting errors for a parabolic shape $(22.7-15.0=7.7 \%)$ and a sinusoidal shape $(19.3-19.1=0.2 \%)$, leads to the conclusion that the sinusoidal approximation is more stable. Summarising, both functions can be used for implementing initial imperfections in numerical models. However, preference is given to the sinusoidal function because it yields more stable results and in addition it is corresponding to the - in this case first - eigenmode, which is often adopted as initial geometrical imperfection in buckling analyses, e.g. in steel constructions.

\section{2. imperfection amplitude}

The allowable imperfection amplitude value of heat-strengthened and tempered glass depends on the manufacturing process and on the standard the glass has to comply with, as listed in Table 3.

Table 3

Maximum allowable values of global bow for heat-strengthened and tempered glass according to product standards EN 1863 and EN 12150-1 respectively [19,20].

\begin{tabular}{|c|c|c|}
\hline Manufacturing process & $\begin{array}{l}\text { Glass to which } \\
\text { applicable }\end{array}$ & $\begin{array}{l}\text { Global bow } \\
(\mathrm{mm} / \mathrm{mm})\end{array}$ \\
\hline Horizontally heat-strengthened & EN 572-2 & 0.003 \\
\hline Horizontally heat-strengthened & Others & 0.004 \\
\hline Vertically heat-strengthened & All & $\begin{array}{l}\text { Dependent on } \\
\text { manufacturer }\end{array}$ \\
\hline Horizontally tempered & EN $572-2$ & 0.003 \\
\hline Horizontally tempered & Others & 0.004 \\
\hline Vertically tempered & All & 0.005 \\
\hline
\end{tabular}


In the following, the influence of several parameters, such as the specimen geometry, the glass type, the effect of lamination and interlayer material on the amplitude of the overall bow of glass beams has been studied. The resulting diagrams are showing the so-called relative imperfection $u_{0} / L$, i.e. the maximal initial

(a) $u_{o} / L[\mathrm{~mm} / \mathrm{mm}]$

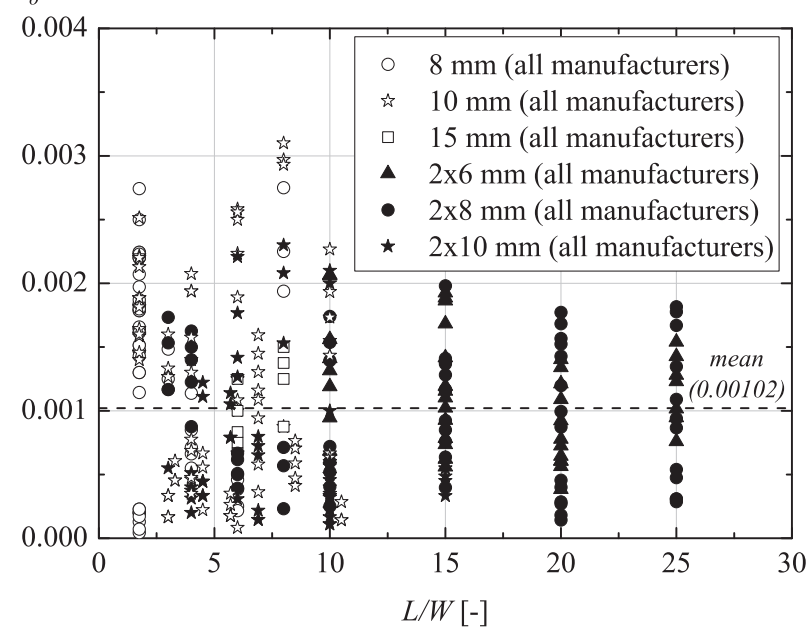

(c) $u_{o} / L[\mathrm{~mm} / \mathrm{mm}]$

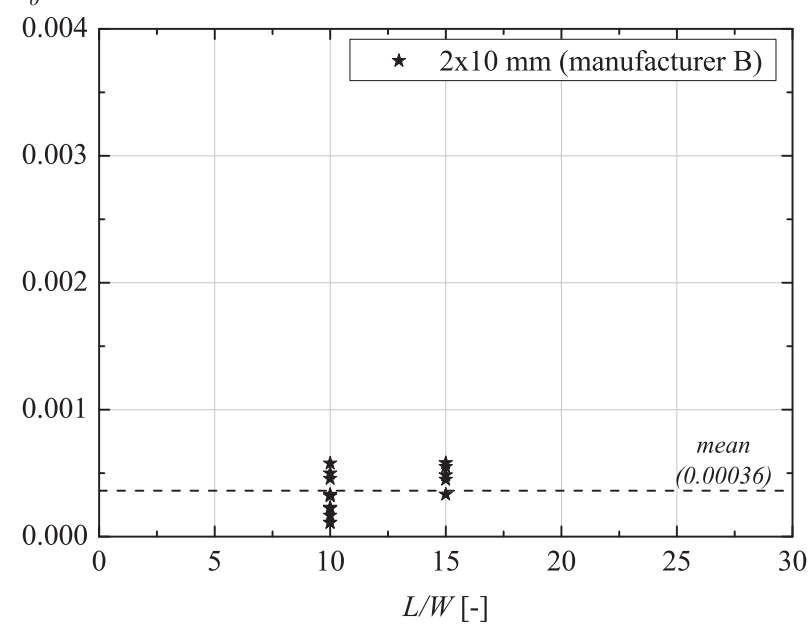

(e) $u_{o} / L[\mathrm{~mm} / \mathrm{mm}]$

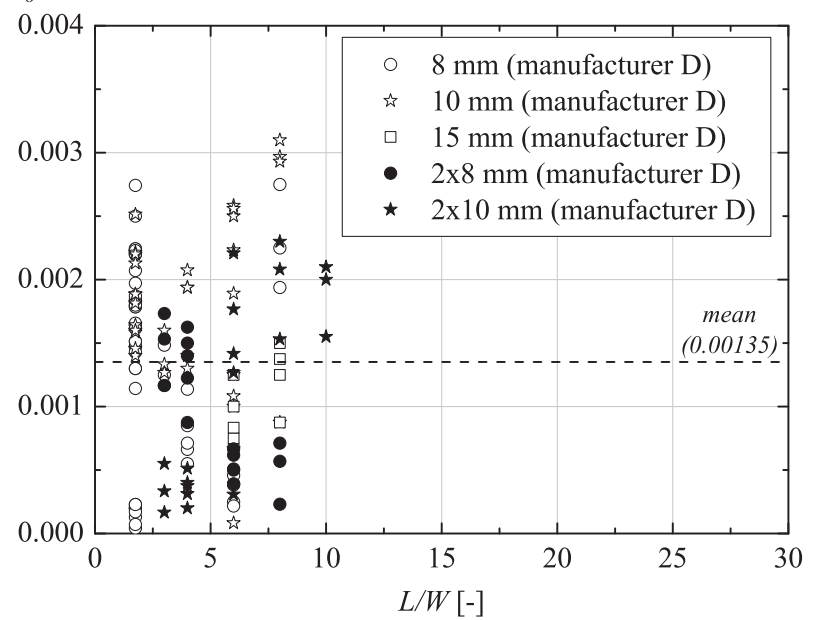

imperfection $u_{0}$ relative to the length $L$, as a function of the aspect ratio $L / W$. Unless stated otherwise, the population considered in the following sections does only consist of the absolute values of the imperfections, in accordance to the results presented in $\S 4.1$.

(b) $u_{o} / L[\mathrm{~mm} / \mathrm{mm}]$

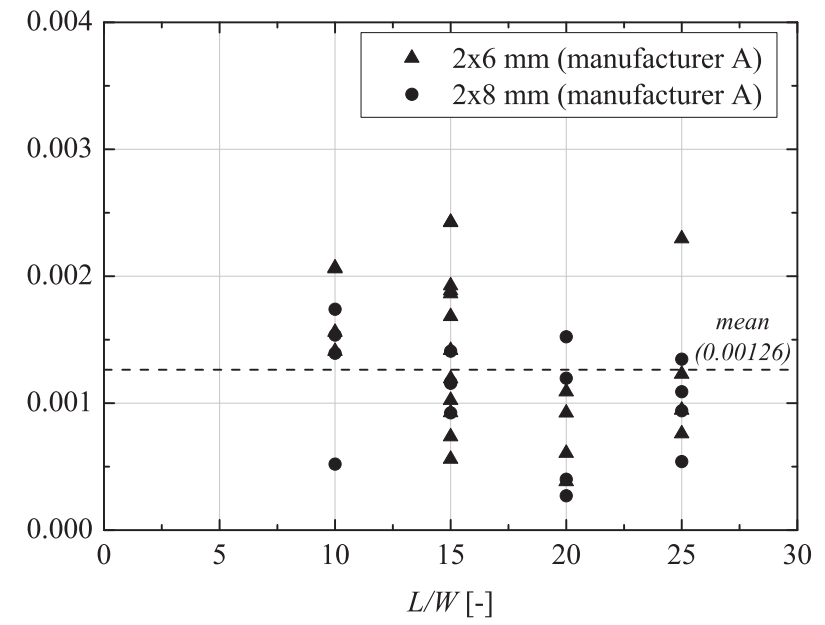

(d) $u_{o} / L[\mathrm{~mm} / \mathrm{mm}]$

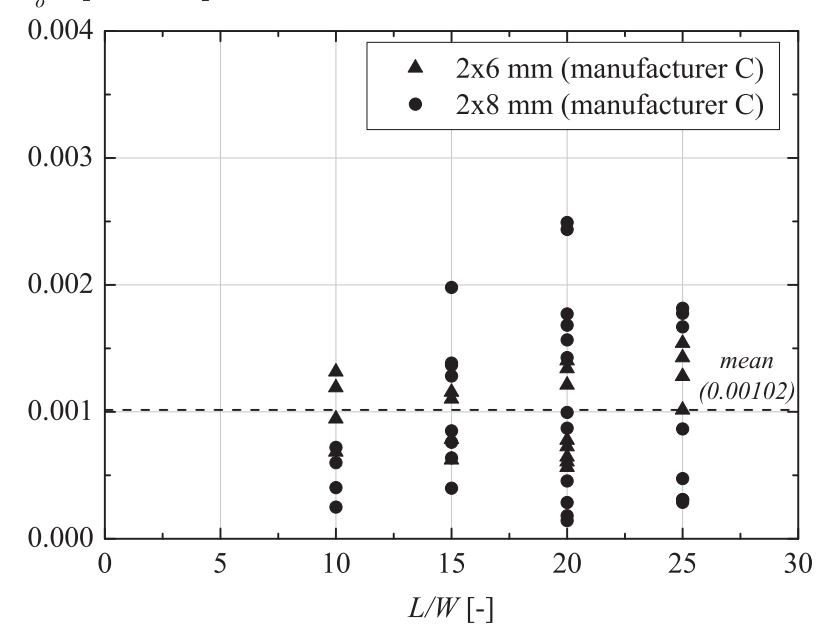

(f) $u_{o} / L[\mathrm{~mm} / \mathrm{mm}]$

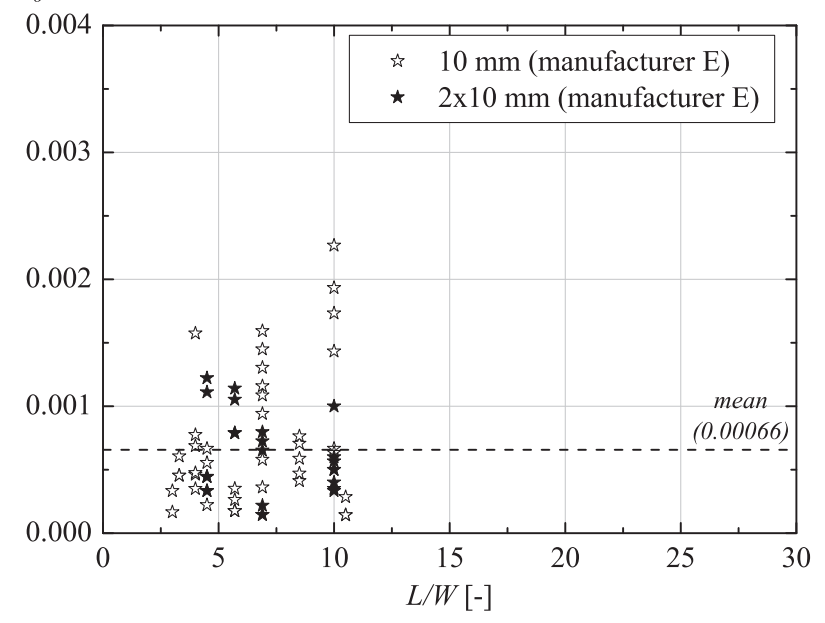

Fig. 11. Initial shape imperfections in relation to the glass thickness for different glass specimens: (a) general overview; (b) by manufacturer A; (c) by manufacturer B; (d) by manufacturer C; (e) by manufacturer D; (f) by manufacturer E. 


\subsubsection{Effect of specimen geometry}

The influence of specimen geometry (i.e. glass thickness and aspect ratio) on the initial shape imperfection is displayed in Fig. 11 for the five different glass manufacturers. All diagrams demonstrate that, except in one case, the amplitude does not exceed the limiting value of $L / u_{0}=0.003$ according to EN 572-2. However, a remarkable influence of the glass thickness or the glass aspect ratio $L / W$ on the imperfection amplitude cannot be identified.

On the other hand, based on Fig. 11a-f it can be assumed that the differences in glass flatness were due to the manufacturer and the specific manufacturing machinery used. This becomes clear when comparing the mean values of the initial imperfection for different manufacturers: whereas the mean value of initial imperfections for the entire set of specimens was 0.00102, the mean initial imperfection for individual manufacturers varied from $0.00036 \mathrm{~mm} / \mathrm{mm}$ (for manufacturer B) to $0.00135 \mathrm{~mm} / \mathrm{mm}$ (for manufacturer D).

\subsubsection{Effect of glass type}

The influence of the glass type (i.e. annealed, heat-strengthened or tempered) on the initial geometric imperfection of monolithic and laminated glass is illustrated in Figs. 12 and 13 respectively. Neither for monolithic nor for laminated glass, a significant difference can be recognized between the imperfection amplitudes of heat-strengthened and tempered glass beams. The authors are aware that quality control of prestress levels of heat-treated glass in industry is not always performed systematically. Consequently, the actual thermally induced residual stresses in the glass may differ significantly from the stress levels assumed in standards. However, based on destructive buckling tests performed later on the same specimens [11,12], the resulting fracture patterns correspond well with what would be expected for heat-strengthened and tempered glass respectively. Consequently, it is reasonable to assume that the stress levels of the heat-strengthened and tempered specimens are within an acceptable range as well.

- the mean value for monolithic heat-strengthened glass was $0.00150 \mathrm{~mm} / \mathrm{mm}$ (see Fig. 12c), versus $0.00100 \mathrm{~mm} / \mathrm{mm}$ for monolithic tempered glass (see Fig. 12d);

- the mean value for laminated heat-strengthened glass was $0.00102 \mathrm{~mm} / \mathrm{mm}$ (see Fig. 13c), versus $0.00105 \mathrm{~mm} / \mathrm{mm}$ for laminated tempered glass (see Fig. 13d).

- On the other hand, the mean initial imperfection of monolithic annealed glass, being $0.00016 \mathrm{~mm} / \mathrm{mm}$ and given in Fig. 12b, is significantly smaller compared to the mean value of $0.00083 \mathrm{~mm} / \mathrm{mm}$ of laminated annealed glass, displayed in (a) $u_{o} / L[\mathrm{~mm} / \mathrm{mm}]$

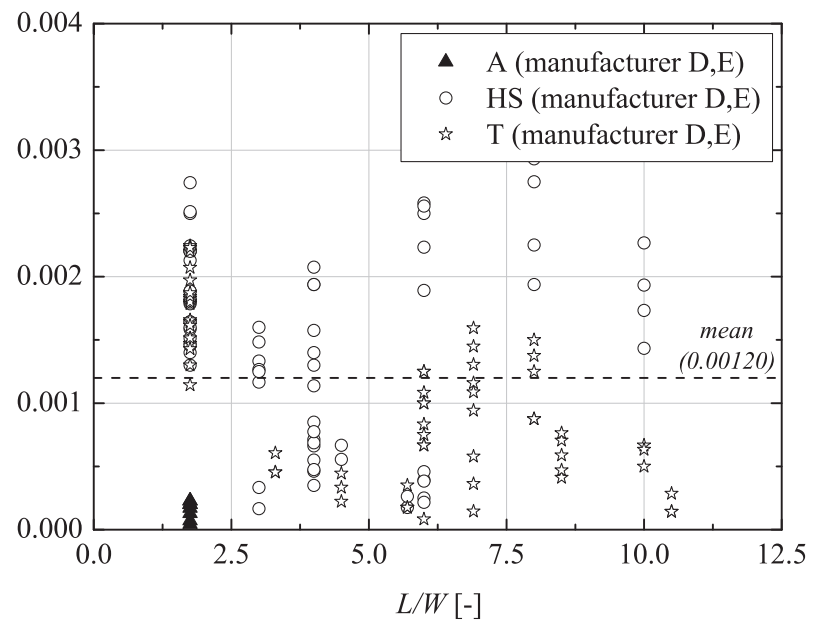

(c) $u_{o} / L[\mathrm{~mm} / \mathrm{mm}]$

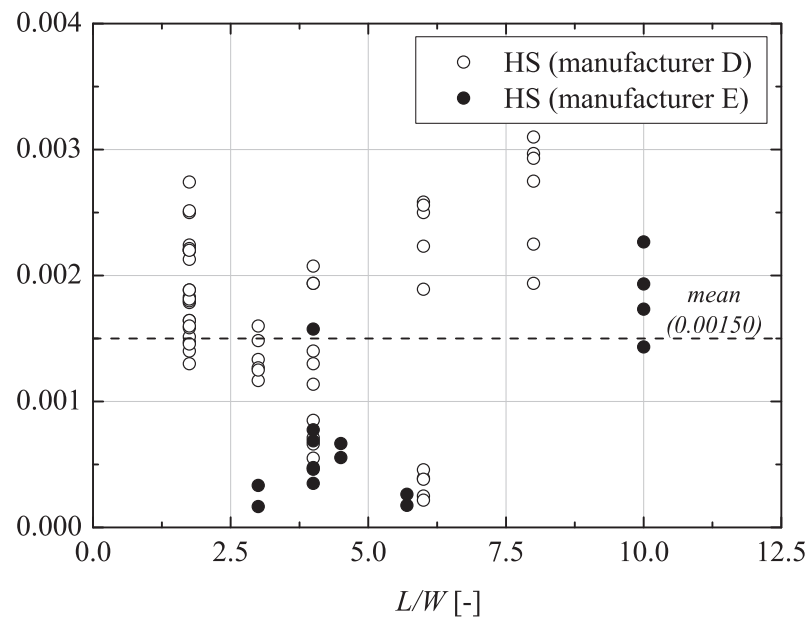

(b) $u_{o} / L[\mathrm{~mm} / \mathrm{mm}]$

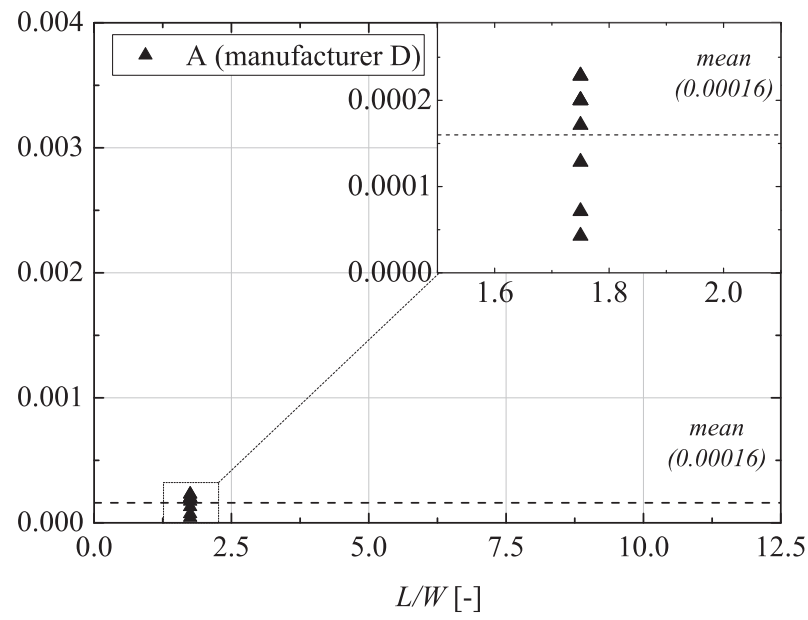

(d) $u_{o} / L[\mathrm{~mm} / \mathrm{mm}]$

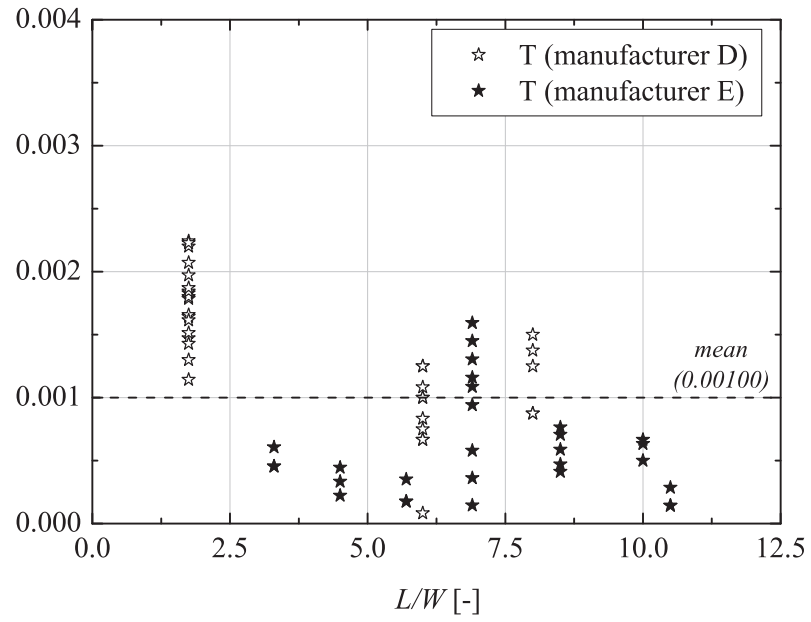

Fig. 12. Initial shape imperfections of monolithic glass specimens: (a) overview of all monolithic glass specimens; (b) annealed glass; (c) heat-strengthened glass; (d) tempered glass. 
(a) $u_{o} / L[\mathrm{~mm} / \mathrm{mm}]$

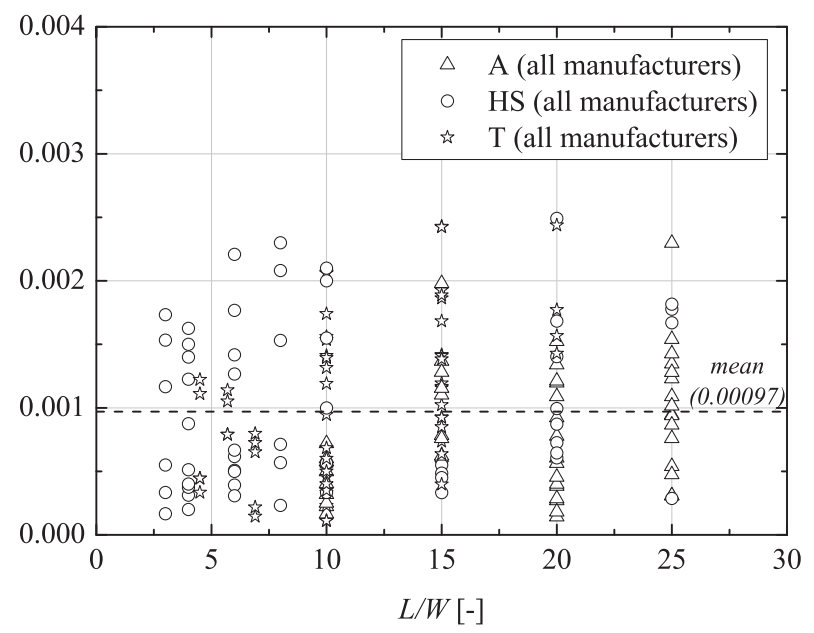

(c) $u_{o} / L[\mathrm{~mm} / \mathrm{mm}]$

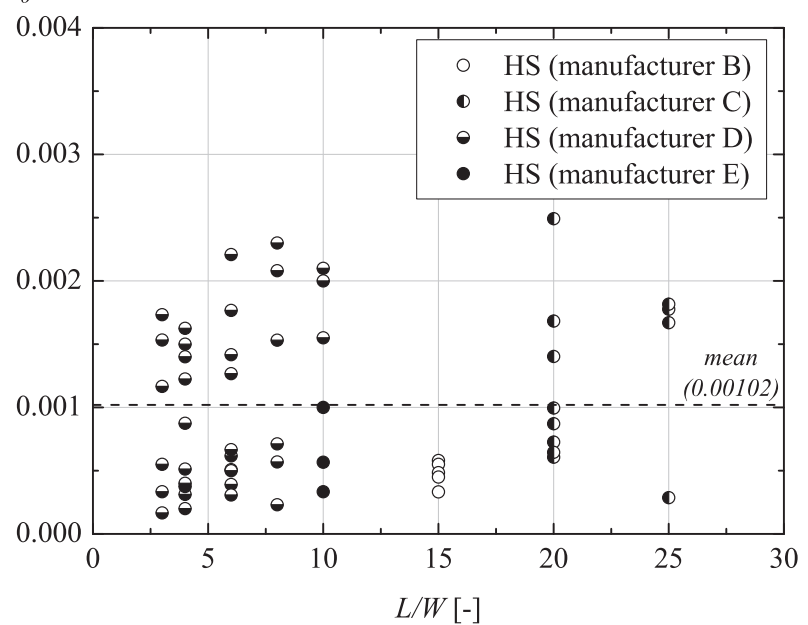

(b) $u_{o} / L[\mathrm{~mm} / \mathrm{mm}]$

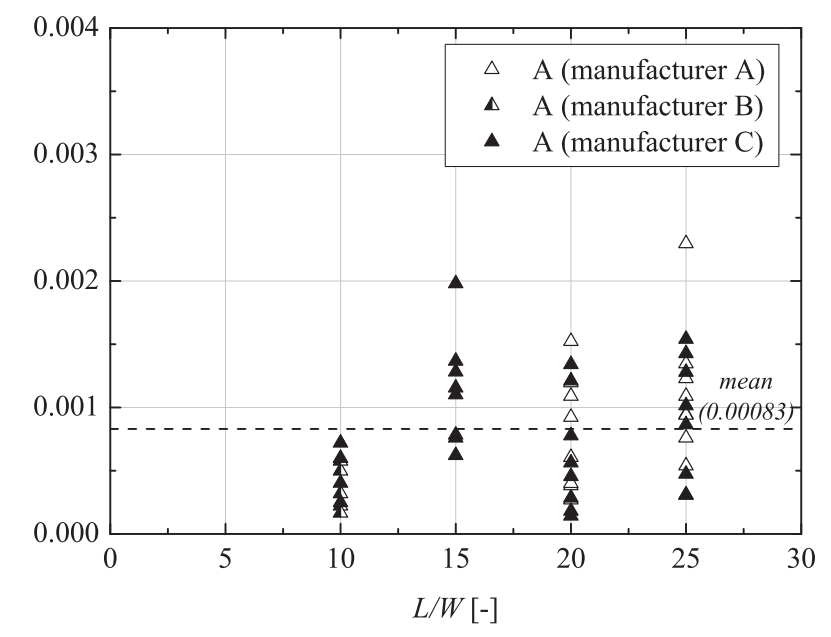

(d) $u_{o} / L[\mathrm{~mm} / \mathrm{mm}]$

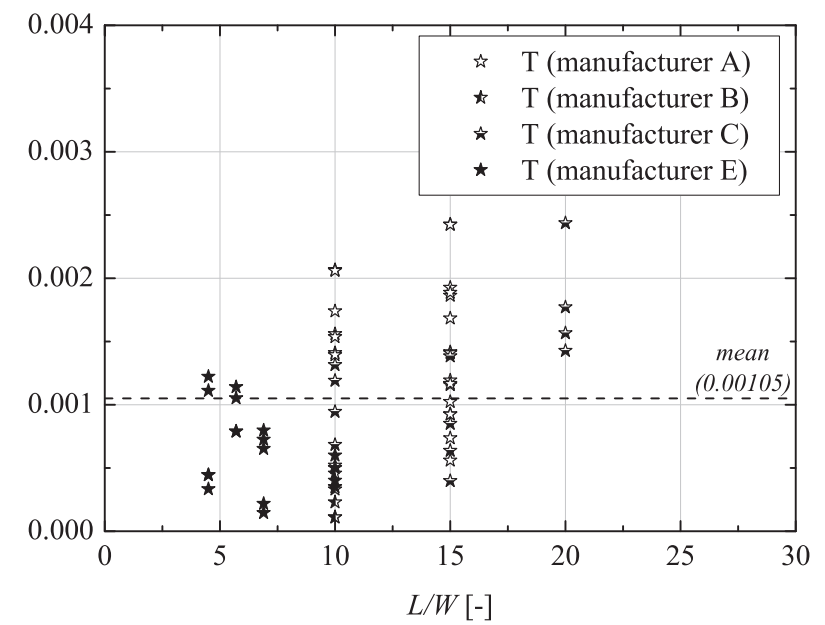

Fig. 13. Initial shape imperfections of laminated glass specimens: (a) overview of all laminated glass specimens; (b) annealed glass; (c) heat-strengthened glass; (d) tempered glass.

Fig. 13b. Consequently, the observed higher initial imperfections of laminated annealed glass compared to monolithic annealed glass seem to be mainly induced by the lamination process, which is a rather surprising conclusion, especially when comparing the relatively equal imperfection amplitudes of monolithic versus laminated heat-strengthened or tempered glass:

- the mean imperfection amplitude for monolithic heat-strengthened glass was $0.00150 \mathrm{~mm} / \mathrm{mm}$ (see Fig. 12c), versus $0.00102 \mathrm{~mm} / \mathrm{mm}$ for laminated heat-strengthened glass (see Fig. 13c);

- the mean imperfection value for monolithic tempered glass amounted to $0.00100 \mathrm{~mm} / \mathrm{mm}$ (see Fig. 12d), whereas $0.00105 \mathrm{~mm} / \mathrm{mm}$ was found for laminated tempered glass (see Fig. 13d).

However, the authors are aware that the number of monolithic annealed glass specimens tested was rather limited and their geometry rather deviant (i.e. with a small aspect ratio $L / W$ ). Consequently, it is recommended to further investigate the influence of the lamination process on the imperfection size based on a larger set of monolithic annealed glass samples with different aspect ratios in future work.

\subsubsection{Effect of lamination and interlayer material}

Each manufacturer has his own production facilities and production methods, which may very well influence the resulting geometrical imperfections, as already demonstrated in \$5.2.2. Therefore, the effect of two different lamination processes of two glass manufacturers on the initial imperfection has been compared. More specifically, glass from manufacturers D and E was investigated, because they supplied monolithic as well as laminated glass, whereas the remaining manufacturers supplied only laminated glass. It can be noticed that the mean imperfection value of glass beams provided by manufacturer $\mathrm{E}$, corresponding to $0.0066 \mathrm{~mm} / \mathrm{mm}$ in Fig. 14b, is slightly smaller compared to the mean value of specimens originating from manufacturer $\mathrm{D}$, equalling $0.00135 \mathrm{~mm} / \mathrm{mm}$ in Fig. 14a. Therefore it is confirmed that the manufacturing process actually does have an influence on the imperfection size.

On the other hand, the interlayer material, i.e. PVB or SG apparently does not influence the maximum value of the glass imperfection of laminated glass, as can be derived from Fig. 15. Manufacturer A supplied laminated glass with PVB as well as SG interlayers and the initial imperfection amplitude for these specimens was $0.00126 \mathrm{~mm} / \mathrm{mm}$, as can be seen in Fig. 15b. On the other hand, manufacturers B and C supplied only laminated glass 
(a) $u_{o} / L[\mathrm{~mm} / \mathrm{mm}]$

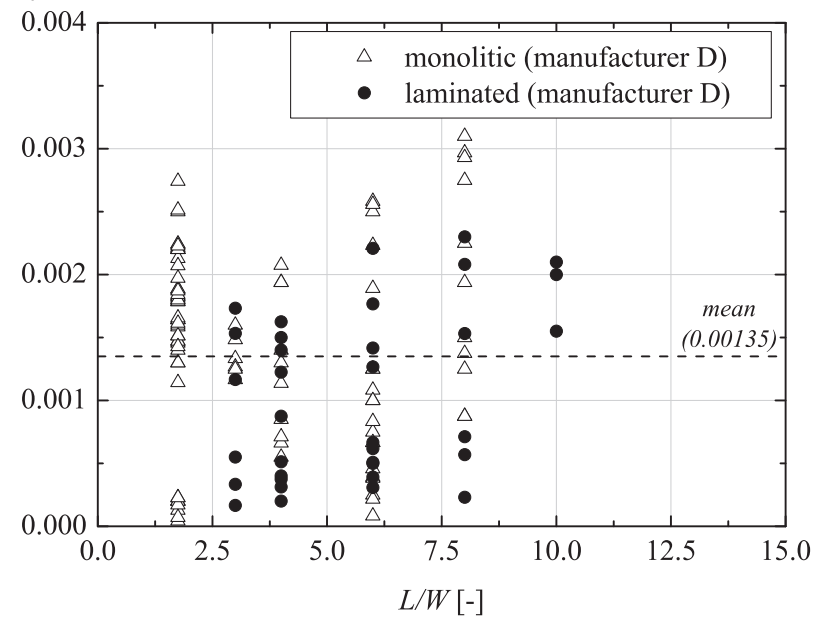

(b) $u_{o} / L[\mathrm{~mm} / \mathrm{mm}]$

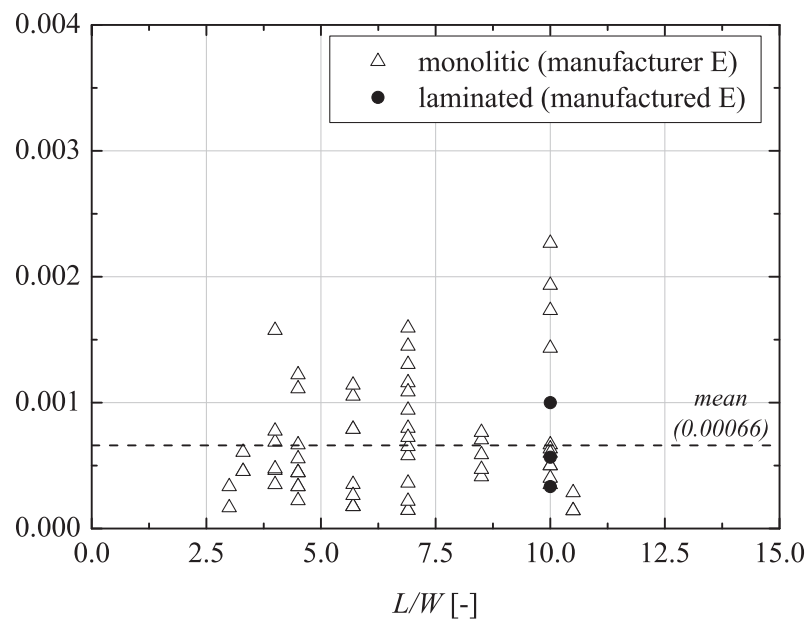

Fig. 14. Comparison of monolithic against laminated glass specimens: (a) manufacturer D; (b) manufacturer E.

(a) $u_{o} / L[\mathrm{~mm} / \mathrm{mm}]$

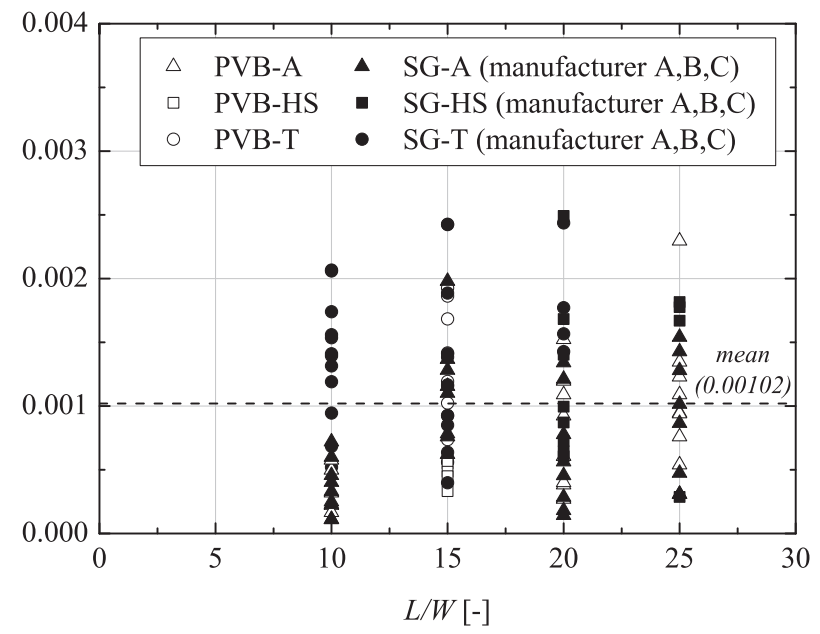

(b) $u_{o} / L[\mathrm{~mm} / \mathrm{mm}]$

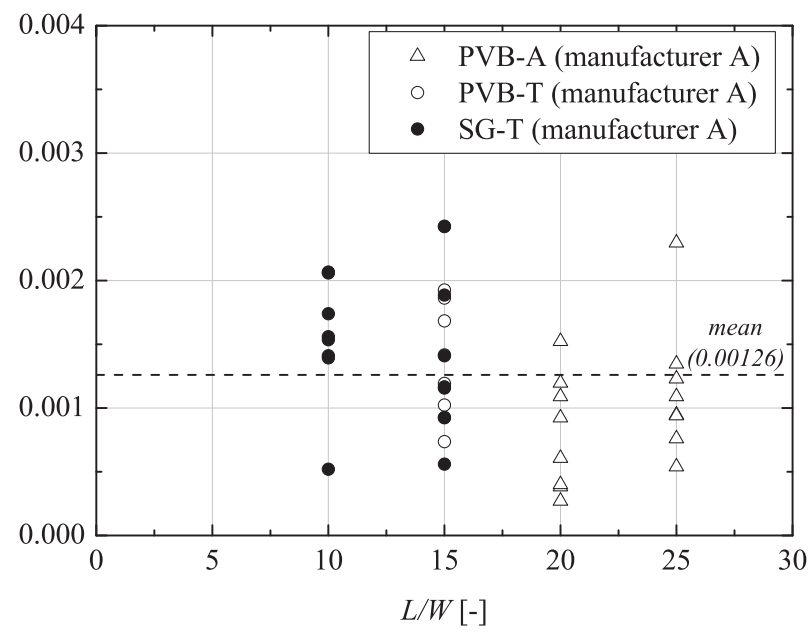

Fig. 15. Comparison of specimens laminated with PVB against specimens laminated with SG: (a) specimens by manufacturer A, B and C; (b) specimens by manufacturer A.

with either PVB or SG interlayers respectively. The overall mean imperfection amplitude for manufacturers A, B and C is 0.00102 $\mathrm{mm} / \mathrm{mm}$, as indicated in Fig. 15a.

\subsection{Characteristic value of initial curvature: discussion}

For practical design purposes, structural engineers will need a characteristic value of the initial geometrical imperfection $\left(u_{0} / L\right)_{c}$, which can be further implemented in buckling analyses. Following common structural engineering practice, the characteristic value for initial geometrical imperfections is defined as the $5 \%$ quantile value. However, care should be taken to calculate this value in a correct way. Two valid approaches are presented and compared below.

\subsubsection{Normal distribution on "doubled" population (624 samples)}

As explained in $§ 4.1$, only positive imperfection results have been obtained, meaning that the overall direction of curvature was the same for all specimens. Obviously, this would not be the case in reality: the curvature might be either concave or convex, and the mean value of a large population should theoretically be zero.
Consequently, as the available data set was based on 312 absolute values only, its distribution is assumed to be a truncated normal distribution with the truncation at zero, in agreement with the Probabilistic Model Code proposed by The Joint Committee on

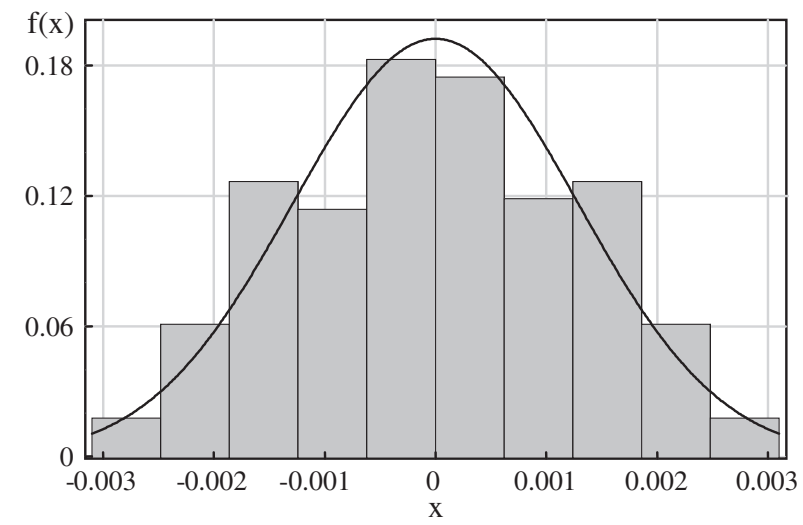

Fig. 16. Untruncated normal distribution fitting and histogram of "doubled" population containing 624 results in total. 
Table 4

Data used to determine the characteristic value of the initial geometrical imperfection of beam-like glass components, based on the experimental data obtained within this research, and corresponding data for each glass manufacturer involved.

\begin{tabular}{llllll}
\hline$u_{0} / L$ & Dimensions & All manuf. & Manuf. A & Manuf. B & Manuf. C \\
\hline Mean value $\mu$ & $(\mathrm{mm} / \mathrm{mm})$ & 0.0000 & 0.0000 & 0.0000 & 0.0000 \\
Min. value & $(\mathrm{mm} / \mathrm{mm})$ & -0.0031 & -0.0024 & -0.0006 & -0.0025 \\
Max. value & $(\mathrm{mm} / \mathrm{mm})$ & 0.0031 & 0.0024 & 0.0006 & 0.0025 \\
Std. dev. $\sigma$ & $(\mathrm{mm} / \mathrm{mm})$ & 0.0013 & 0.0014 & 0.0004 & 0.0000 \\
Characteristic value & $(\mathrm{mm} / \mathrm{mm})$ & 0.0025 & 0.0027 & 0.0008 & 0.0031 \\
Number of specimens & $(-)$ & 624 & 80 & 30 & 0.0023 \\
\hline
\end{tabular}

Structural Safety (JCS) [21]. This truncated normal distribution is equivalent to a normal distribution which corresponds to a modified population. More specifically, the available data set was considered twice, whereas one time it was given a negative sign and the other it kept a positive sign. Consequently, a new population of 624 imperfection values was obtained with a mean imperfection value equal to zero and an equivalent untruncated normal distribution, depicted in Fig. 16.

Subsequently, from this "doubled" population the characteristic value is calculated. In general, to get the $5 \%$ quantile the expression displayed in Eq. (9) is applied, in which $\mu$ represents the mean value and $\sigma$ is the standard deviation of the fitted curve:

$5 \%$ quantile $=\mu+1.645 * \sigma$

However, because the results have been "doubled" to obtain a correct data set, our interest is to get the 2.5 quantile on each tail of the untruncated normal distribution function, i.e. on the positive and on the negative side. Consequently, in this case Eq. (9) should be modified, as expressed in the following equation:

$$
\begin{aligned}
(5 \% \text { quantile })_{\text {truncated distribution }} & =(2.5 \% \text { quantile })_{\text {untruncated distribution }} \\
& =\mu+1.96 * \sigma
\end{aligned}
$$

Finally, based on this method, the resulting characteristic value for the initial geometrical imperfection of beam-like glass components $\left(u_{0} / L\right)_{c}$ is $0.0025 \mathrm{~mm} / \mathrm{mm}$, as displayed in Table 4 .

Table 5

Goodness of fit results according to different tests obtained for a Johnson SB distribution of the original population containing 312 measurement results.

\begin{tabular}{lllcl}
\hline Test & $\begin{array}{l}\text { Significance } \\
\text { level }(\%)\end{array}$ & $\begin{array}{l}\text { Test } \\
\text { statistic }(-)\end{array}$ & $\begin{array}{l}\text { Critical } \\
\text { value }(-)\end{array}$ & $\begin{array}{l}\text { Null } \\
\text { hypothesis }\end{array}$ \\
\hline $\begin{array}{l}\text { Kolmogorov Smirnov } \\
\text { Chi-Square }\end{array}$ & 5 & 0.052 & 0.077 & Not rejected \\
& 5 & 13.65 & 15.51 & Not rejected \\
\hline
\end{tabular}

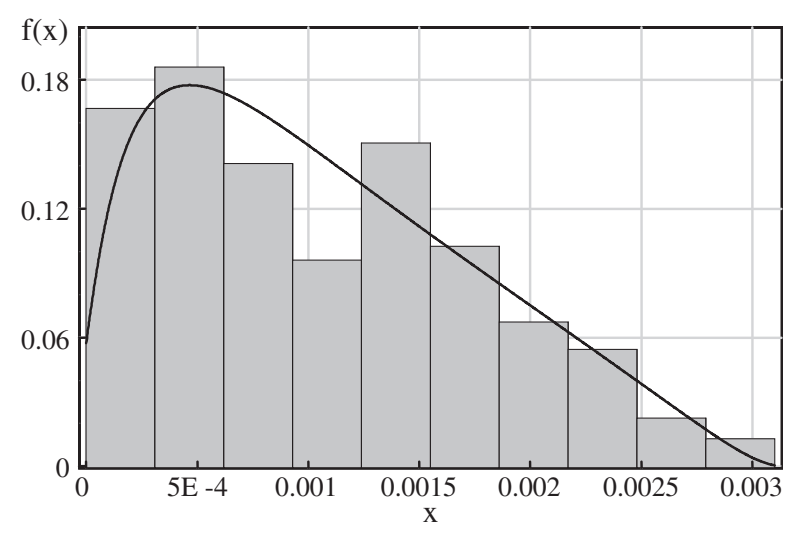

Fig. 17. Johnson SB distribution fitting and histogram of the original population containing 312 results in total.
5.3.2. Johnson SB distribution on original population (312 samples)

An alternative approach is to analyse directly the asymmetric probability density function based on the original 312 imperfection measurement values only. As it is crucial to use the best fitting statistical distribution, the goodness of fit of over 50 different distributions has been compared. The comparison comprised, among many others, a lognormal, Weibull, error and general extreme value distribution.

The goodness of fit is estimated according to the Kolmogorov Smirnov test and the Chi-Squared test. The null hypothesis for both tests is that the data follow the specified distribution. In other words, a good fit of the chosen distribution means that the null hypothesis is not rejected. The hypothesis regarding the distributional form is rejected at a chosen significance level if the test statistic is greater than a critical value. In this analysis, a commonly used significance level of $5 \%$ is adopted.

The best fit is found for a Johnson SB distribution. The goodness of fit test results are displayed in Table 5; the corresponding distribution function and histogram are depicted in Fig. 17. Finally, the $5 \%$ quantile of the Johnson SB distribution yields a characteristic value of $0.0024 \mathrm{~mm} / \mathrm{mm}$.

\subsubsection{Comparison of both approaches}

A possible critic to the method of the JCS is that the maximum density is found for an amplitude of zero, as can be seen in Fig. 16. In other words, the most frequently found amplitude is supposed to be zero, which obviously is not realistic. However, only values very close to zero are not acceptable; the rest of the distribution definitely is, as is proven by the good fit.

Additionally, both approaches yield almost identical results, namely $0.0025 \mathrm{~mm} / \mathrm{mm}$ and $0.0024 \mathrm{~mm} / \mathrm{mm}$ respectively. From these values, it can be concluded that the characteristic value which should be considered for design purposes is about $17 \%$ smaller compared to the maximum allowable value of overall bow determined in the most stringent product standards for heatstrengthened and tempered glass, tabled in Table 3. Expressed as a fraction of the beam length $L$, the characteristic value of the amplitude equals $L / 400$.

\section{Conclusions}

In this contribution, an extended experimental campaign was presented to investigate the shape and size of initial geometrical imperfections (curvature) of structural glass components, i.e. glass beams, fins and columns. The most important conclusions are summarised below. However, it should be noted that only beam-like specimens (i.e. $W<<L$ ) have been investigated here. Consequently, one should be careful to adopt the conclusions when dealing with smaller aspect ratios $L / W$.

\subsection{Imperfection shape}

Detailed experimental measurements and fitting error analyses revealed that the shape of typical initial geometrical imperfections 
could be approximated well by parabolic and sinusoidal functions for the whole population, i.e. regardless of glass type, lamination, glass size or manufacturer. However, it should be noted that for an insignificantly small number of atypical specimens a significantly deviating shape has been found as well. In general, both parabolic and sinusoidal approximate shape functions may be used, even though the authors have a preference for sinusoidal functions because they correspond to eigenmodes resulting from elastic buckling theory.

\subsection{Imperfection amplitude}

As it was not clear what the amplitude of the global bow of glass beams and columns is depending on, the influence of different parameters has been experimentally investigated. The latter include the specimen geometry, the glass type, the lamination process and the interlayer material. The most important conclusions are listed below:

1. Obviously, longer glass specimens generally correspond to a larger absolute value of the initial imperfection. No clear influence of the glass aspect ratio $L / W$ or glass thickness on the imperfection amplitude could be detected.

2 . As the maximum relative imperfection $u_{0} / L$ was 0.0031 , practically all measured imperfection values are within the limits given by glass product standards. However, it should be noted that the latter exist for heat-strengthened and tempered glass only. Even if this lack of global bow restrictions for annealed glass seems to suggest that no significant imperfections have to be considered for annealed glass, this is definitely contradicted by the experimental results on laminated annealed glass. For the latter, the size of global geometrical imperfections can easily equal that of heat-treated glasses. Finally, no noticeably different imperfections sizes have been found for heatstrengthened and tempered glass.

3. Further analysis of initial geometrical imperfections of annealed glass surprisingly yielded results which were very different whether it was monolithic or laminated. For the first, imperfections were found which were generally significantly smaller compared to heat-treated glasses, as expected. However, for the latter this was not the case anymore. Consequently, it is concluded that the laminating process can induce important additional imperfections, which are definitely not negligible in case of annealed glass.

4. Subsequently, geometrical imperfections of laminated specimens composed with two different interlayer types, known to have a significantly different stiffness at ambient conditions, have been compared. However, according to the result, no influence of the interlayer type on the imperfection size was found.

5. Next, it should be noted that significantly different initial geometrical imperfection values have been found between different manufacturers. Even if none of the manufacturers failed to meet the product standards, it is clear that geometrical imperfections can be controlled better depending on the machines, processes and expert knowledge of the manufacturer.

6. Finally, based on the experimental results a characteristic value of $0.0025 \mathrm{~mm} / \mathrm{mm}$ was defined for the initial geometrical imperfection of glass beams $u_{0} / L$, which is about $17 \%$ smaller compared to the maximum allowable value of global bow determined in the most stringent product standards for heatstrengthened and tempered glass.

\section{Acknowledgements}

BRS (NL), GlasTrösch SA (CH), DuPont de Nemours (B), Lerobel (Groep Leroi, B), van Noordenne Groep (NL) and VIM - Verres Industriels Moutier SA (CH) (in alphabetical order) are gratefully acknowledged for the testing materials.

\section{References}

[1] www.glassfiles.com, July 2010.

[2] Schittich C, Staib G, Balkow D, Schuler M, Sobek W. Glass construction manual. Basel: Birkhäuser Verlag AG; 2007.

[3] Wurm J. Glass structures-design and construction of self-supporting skins. Basel, Boston, Berlin: Birkhäuser Verlag AG; 2007.

[4] Shen X. Entwicklung eines Bemessungs- und Sicherheitskonzeptes für den Glasbau. Darmstadt: Technische Hochschule Darmstadt; 1997.

[5] Güsgen J. Bemessung tragender Bauteile aus Glas. Aachen: Shaker Verlag; 1998.

[6] Veer FA, Louter PC, Bos FP. The strength of annealed, heat-strengthened and fully tempered float glass. Fatigue Fract Eng M 2009;32:18-28.

[7] Haldimann M. Fracture strength of structural glass elements. Lausanne: Ecole Polytechnique Fédérale de Lausanne; 2006.

[8] Overend M, Parke G, Buhagiar D. A general crack growth model for predicting failure in glass. J Struct Eng ASCE 2007;133:1146-210.

[9] Mocibob D, Belis J. Coupled experimental and numerical investigation of structural glass panels with small slenderness subjected to locally introduced axial compression. Eng Struct 2010;32(3):753-9.

[10] Liess J. Bemessung druckbelasteter Bauteile aus Glas. Kassel: Books on Demand GmbH, Universität Kassel; 2001

[11] Luible A. Stabilität von Tragelementen aus Glas. Lausanne: Ecole Polytechnique Fédérale de Lausanne; 2004.

[12] Belis J. Kipsterkte van monolithische en gelamineerde glazen liggers. Ghent: Ghent University; 2005.

[13] Kasper R. Tragverhalten von Glasträgern. Aachen: Shaker Verlag Gmbh, RWTH Aachen; 2005

[14] Blauwendraad J. Buckling of laminated glass columns. Heron 2007;52(1/2): 147-218

[15] Englhardt O. Flächentragwerke aus Glas-Tragverhalten und Stabilität. Vienna: Universität für Bodenkultur Vienna; 2007.

[16] Blauwendraad J. Buckling of laminated glass columns. Comparison and replacement. In: Bos F, Louter PC, Veer F, editors. Challenging glass. Amsterdam: IOS Press BV; 2008. p. 323-8.

[17] Mocibob D. Glass panels under shear loading-use of glass envelopes in building stabilization. Lausanne: Ecole Polytechnique Fédérale de Lausanne; 2008.

[18] Lindner J, Holberndt T. Zum Nachweis von stabilitätsgefährdeten Glasträgern unter Biegebeanspruchung. Stahlbau 2006;75(6):488-511.

[19] EN 1863-1:2000. Glass in building - heat-strengthened soda lime silicate glass - part 1: definition and description. CEN; 2000.

[20] EN 12150-1:2000. Glass in building - thermally toughened soda lime silicate safety glass - part 1 : definition and description. CEN; 2000.

[21] JCSS probabilistic model code. The joint committee on structural safety, 2001 (www.jcss.ethz.ch) 